\title{
Drug-Induced Liver Injury: Highlights and Controversies in the Recent Literature
}

\author{
Joseph William Clinton ${ }^{1}\left[\right.$ ] Sara Kiparizoska ${ }^{1} \cdot$ Soorya Aggarwal ${ }^{2} \cdot$ Stephanie Woo $^{1} \cdot$ William Davis $^{1}$ - James H. Lewis ${ }^{2}$
}

Accepted: 5 August 2021 / Published online: 17 September 2021

(c) The Author(s), under exclusive licence to Springer Nature Switzerland AG 2021

\begin{abstract}
Drug-induced liver injury (DILI) remains an important, yet challenging diagnosis for physicians. Each year, additional drugs are implicated in DILI and this year was no different, with more than 1400 articles published on the subject. This review examines some of the most significant highlights and controversies in DILI-related research over the past year and their implications for clinical practice. Several new drugs were approved by the US Food and Drug Administration including a number of drugs implicated in causing DILI, particularly among the chemotherapeutic classes. The COVID-19 pandemic was also a major focus of attention in 2020 and we discuss some of the notable aspects of COVID-19-related liver injury and its implications for diagnosing DILI. Updates in diagnostic and causality assessments related to DILI such as the Roussel Uclaf Causality Assessment Method are included, mindful that there is still no single biomarker or diagnostic tool to unequivocally diagnose DILI. Glutamate dehydrogenase received renewed attention as being more specific than alanine aminotransferase. There were a few new reports of previously unrecognized hepatotoxins, including immune modulators and novel gene therapy drugs that we highlight. Updates and new developments of previously described hepatotoxins, such as immune checkpoint inhibitors and anti-tuberculosis drugs are reviewed. Finally, novel technologies such as organoid culture systems to better predict DILI preclinically may be coming of age and determinants of hepatocyte loss, such as calculating $\mathrm{P}_{\mathrm{ALT}}$ are poised to improve our current means of estimating DILI severity and the risk of acute liver failure.
\end{abstract}

\section{Introduction}

Drug-induced liver injury (DILI) remains a challenging diagnosis for physicians and is an area of ongoing research efforts. Each year, DILI gains increased attention from physicians, researchers, and patients alike as it poses a significant risk to patient health and healthcare costs. Ke et al. published the first scientometric study on knowledge mapping of DILI in which they reviewed articles published from 2010 to 2019 in the Web of Science Core Collection and found 1995 publications from 592 academic journals by 2331 institutions from 79 countries/regions [1]. The number of publications on DILI is increasing each year as shown in Fig. 1, with much of the focus on its definition,

Joseph William Clinton

joseph.w.clinton@medstar.net

1 Department of Internal Medicine, Medstar Georgetown University Hospital, Washington, DC, USA

2 Division of Gastroenterology and Hepatology, Medstar Georgetown University Hospital, Washington, DC, USA incidence rates/clinical characteristics, etiology/pathogenesis, and causality assessment. The Roussel Uclaf Causality Assessment Method (RUCAM) continues to increase in use as a causality assessment tool, especially outside of the USA [2]. While RUCAM provides for an objective scoring system, a degree of expertise in DILI assessment is still required to best interpret and calculate its various diagnostic elements and overcome its limitations, which will be discussed. The search for new diagnostic biomarkers of DILI continued this past year, with much interest in genetic markers and other predictive serum markers.

The aim of this review is to highlight what we considered the most impactful DILI-related research over the past year. We specifically focused on publications that improve our ability to diagnose DILI and perform a causality assessment, provide data on new hepatotoxins, and update our knowledge base for previously known hepatotoxins. The COVID-19 pandemic was certainly the most important area of concern among patients, physicians, and researchers alike in 2020, and the relationship between COVID-19 and liver injury, including DILI, was front and center among the extrapulmonary manifestations of the disease. In some instances, it 


\section{Key Points}

Drug-induced liver injury (DILI) remains a challenging diagnosis for physicians, and while there is still no definitive diagnostic biomarker, glutamate dehydrogenase may be more specific than alanine aminotransferase.

Each year, new drugs are implicated as potential hepatotoxins, especially those in the oncology space, including tyrosine kinase inhibitors and checkpoint inhibitors.

The COVID-19 pandemic created numerous challenges for drug development and we discuss liver injury related to COVID-19, including the potential for DILI during its treatment.

New developments in the clinical signatures and mechanisms of injury from previously described hepatotoxins are discussed, including current controversies in the management of immune checkpoint inhibitors and antituberculosis-related DILI.

Novel technologies, including organoid culture systems, that are being developed to predict DILI in drug development and estimate severity of DILI are discussed. was difficult to determine whether hepatic injury was due to the virus, or the drugs involved with treatment, as instances of DILI have been reported [3].

\section{Methods}

We performed an extensive search of the literature using the PubMed database as well as reviewing the major gastrointestinal and hepatology-based journals since our last reviews were published in 2020 covering most of the 2019 year $[4,5]$. For the most part, for this current review, we included publications from journals with an impact factor of 1.0 and above using the Impact Factor List of 2020 from the Journal Citation Report to assess the journal's impact factor, in order to ensure that studies and reports were of high quality [6]. Our search terms included: drug induced liver injury, DILI, hepatotoxicity, and RUCAM. We restricted our search to articles published in the English language. Authors JC, SK, SA, SW, WD, and JHL performed the literature search and included articles from September 2019 to February 2021, which yielded over 1400 articles relating to DILI (Fig. 1). Our search was then focused on those articles containing updates in diagnosis and causality assessments, newly described hepatotoxins, new reports of previously established hepatotoxins, updates on treatment of DILI, and COVID-19-related liver injury. We excluded
Fig. 1 Methodology for literature review. DILI drug-induced liver injury, RUCAM Roussel Uclaf Causality Assessment Method

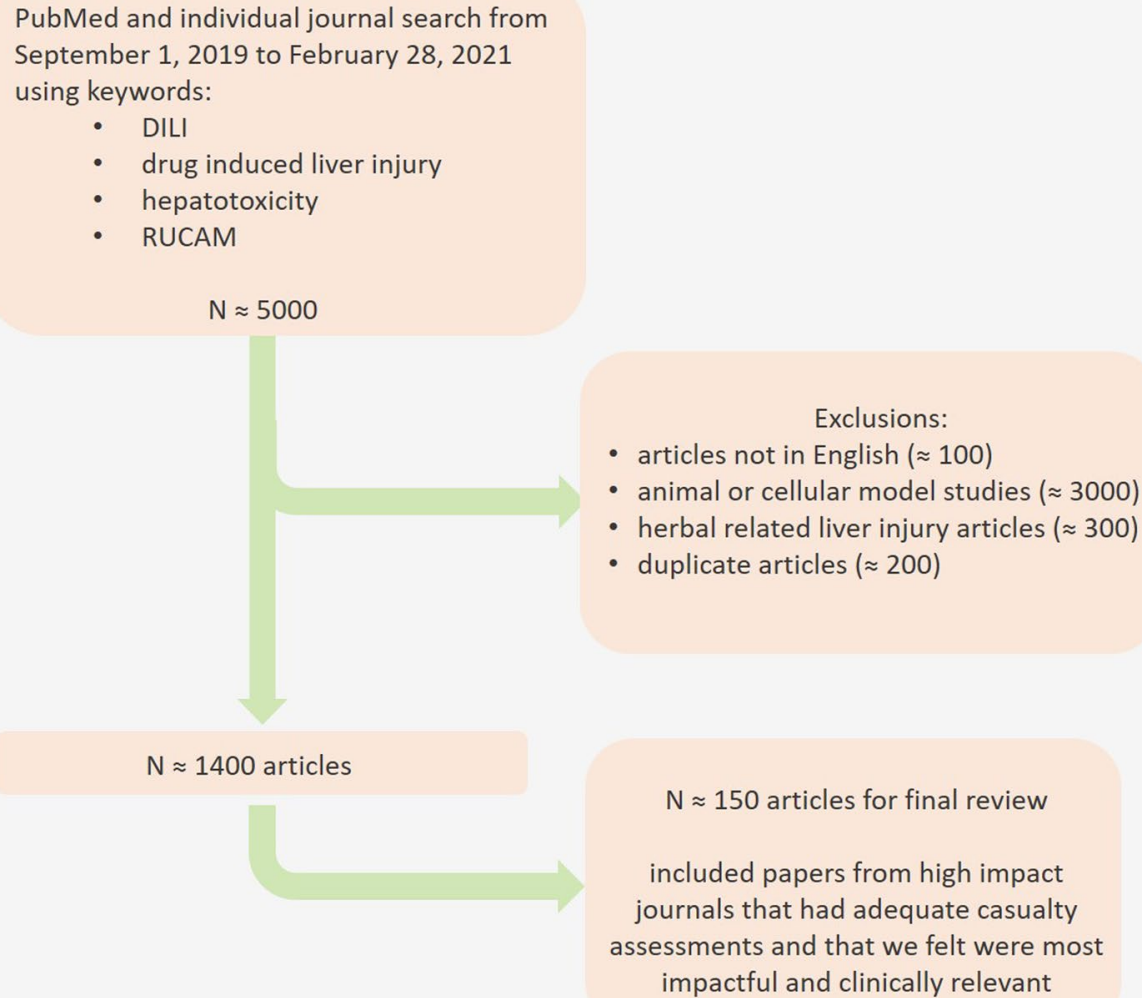


articles with animal or cellular models unless there was a significant clinical implication. Liver injury from herbal and dietary supplements were not included, as they are the subject of a separate review. Data extracted included author names, journal name, publication date, article title, volume number, issue number, page numbers, and any information we chose to discuss from the article body. Authors who performed the literature search then added articles to a shared document where each author further reviewed articles to ensure they were from high-quality journals, had some type of causality assessment, and to remove any duplicate articles. Approximately 150 articles on DILI were included in this review, including a variety of studies and case reports. As in past years, we attempted to highlight those case reports with a reported RUCAM or expert opinion score of at least "probable" [7, 8].

\section{New FDA Drug Approvals and DILI}

Despite the challenges from a worldwide pandemic, the US Food and Drug Administration (FDA) was successful in approving several novel drugs in the USA the past year, with 53 new approvals in 2020 [9]. At the time of this writing, nine drugs have already approved in 2021. These approvals were in several different treatment categories with oncology (34\%), neurology (15\%), and infectious disease (13\%) drugs leading the pack. Importantly, 36 of these $62(58 \%)$ FDA drugs approved in 2020 and 2021 had mention of liver toxicity, either in their clinical trial results or listed in the official FDA drug label.

Although most of these agents are still quite new and published reports of DILI have not appeared, Fig. 2 shows the proportion of each drug category that had any mention of hepatotoxicity during their clinical trials or in the product label. The majority of these new drugs were chemotherapeutic agents (18 out of 21) followed by agents used to treat infectious diseases (7 out of 8 ) and neurologic disorders (5 out of 9). Twelve of the novel drugs (nearly 20\%) had hepatotoxicity warnings and/or precautions specifically listed in their FDA label. These drugs are included in Table 1. Chemotherapeutic agents make up the majority of these agents with six of them being tyrosine kinase inhibitors.

\section{COVID-19 and Liver Injury}

The coronavirus pandemic dominated clinical concerns and research in 2020, which continues into 2021. It impacted clinical trials for new drugs and was associated with hepatic enzyme elevations that in some cases posed a significant confounder in the diagnosis of DILI.

\subsection{COVID-19-Related Liver Injury}

Liver enzyme abnormalities are common in hospitalized patients with COVID-19, with an estimated range of 14-53\% [10-13]. The most common pattern of injury is a mild-tomoderate hepatocellular injury (aspartate aminotransferase/ alanine aminotransferase [AST/ALT] $<5 \times$ upper limit of normal [ULN]). The exact pathophysiologic mechanism whereby COVID-19 causes hepatic injury is not yet fully elucidated, but various mechanisms have been implicated including, direct viral injury, immune-mediated injury, hypoxia-related injury, exacerbation of pre-existing liver disease, or even treatment-related DILI, given the wide spectrum of medications that had been given for the treatment of severe COVID-19 [14].

On a biochemical level, the angiotensin-converting enzyme 2, a host cell receptor for SARS-CoV that has been shown to mediate SARS-CoV-2 infection, is found in considerably higher concentrations in cholangiocytes $(59.7 \%)$ compared with hepatocytes (2.6\%) [15-18]. Nonetheless, the pattern of liver injury in COVID-19 is typically hepatocellular with mild-to-moderate aminotransferase elevations, suggesting that direct viral injury is not a major mechanism of the liver injury. Instead, many researchers propose an underlying systemic immune reaction as the etiology for COVID-19-related liver injury. This has been supported by increased levels of inflammatory cytokines and other inflammatory markers such as tumor necrosis factor- $\alpha$, interleukin (IL)-2, IL-6, IL-7, IL-18, granulocyte-macrophage colonystimulating factor, interferon $\gamma$, and ferritin in patients with COVID-19 [19].

Interestingly, COVID-19 infection has not been associated with laboratory markers of liver synthetic dysfunction and is rarely associated with acute liver failure in patients without pre-existing chronic liver disease [14]. Therefore, the enzyme abnormalities in COVID-19 infection appear to be less clinically significant than originally thought. Patients with pre-existing chronic liver diseases are theorized to be at increased risk for COVID-19 infection because of their relative immunodeficiency, although this relationship has not been fully clarified [20].

\subsection{COVID-19 Infection-Related DILI}

Several drugs used in the treatment of COVID-19 have been theorized as potential causes of DILI, though evidence of a causal relationship is limited. Cai et al. looked at 417 patients with COVID-19 in a study in China that showed th euse of lopinavir/ritonavir increased the odds of liver injury by four-fold compared with a patient who did not receive the drug [21]. However, previous studies have suggested that moderate-to-severe elevations in serum aminotransferase 
Fig. 2 Proportion of each drug category that had any mention of hepatotoxicity in their official US Food and Drug Administration label or trial separated by clinical category of use [9].

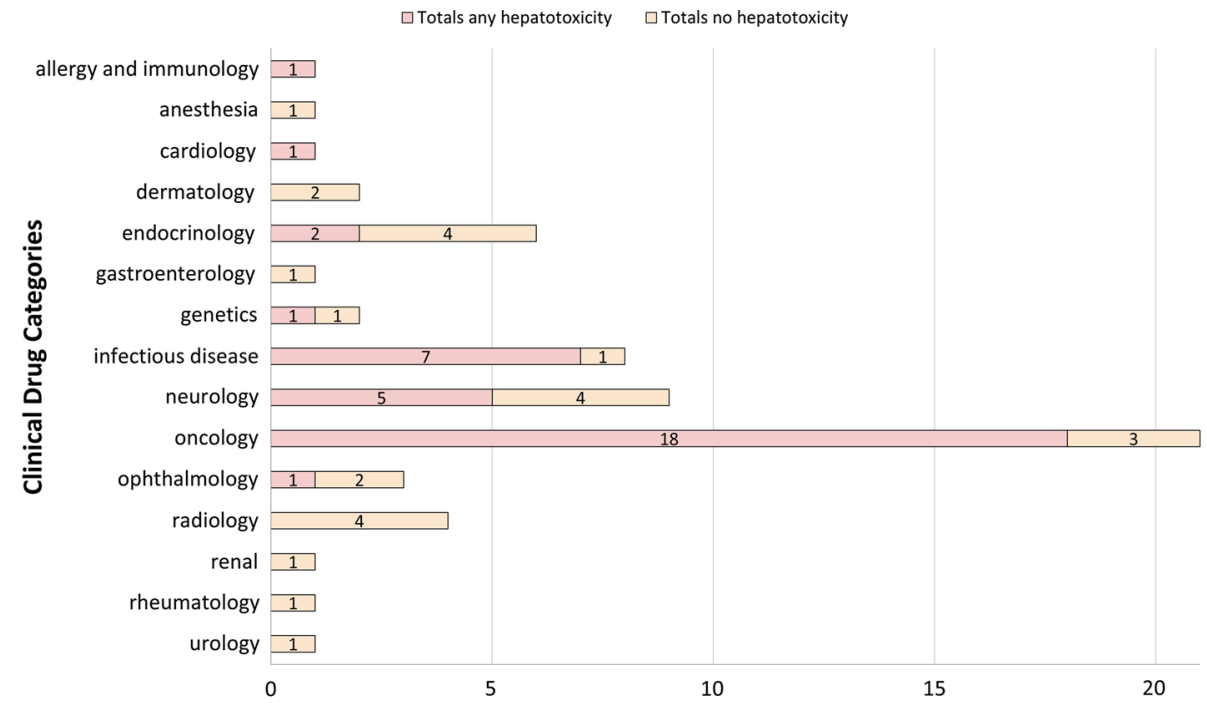

Table 1 New drug approvals from 2020 and 2021 with a US Food and Drug Administration label listing a warning or precaution for hepatotoxicity [9]

\begin{tabular}{|c|c|c|c|}
\hline Drug name & Indication & Mechanism & Type of liver injury in clinical trials \\
\hline $\begin{array}{l}\text { Cabotegravir } \\
\text { and rilpiv- } \\
\text { irine }\end{array}$ & HIV & Antiretroviral agent & $\begin{array}{l}\text { Grade } 3 \text { or } 4^{\mathrm{a}} \text { AST or ALT elevations in } 2 \% \text { of } \\
\text { patients }\end{array}$ \\
\hline Capmatinib & Non-small cell lung cancer & Kinase inhibitor & $\begin{array}{l}\text { AST or ALT elevations in } 13 \% \text {. Grade } 3 \text { or } 4 \text { AST/ } \\
\text { ALT elevations in } 6 \% \text { of patients }\end{array}$ \\
\hline Fostemsavir & HIV & Antiretroviral agent & $\begin{array}{l}\text { Elevations in hepatic transaminases in patients } \\
\text { with hepatitis B or C virus co-infection (Grade } 3 \\
\text { or } 4 \text { in } 14 \% \text { ) }\end{array}$ \\
\hline Lurbinectedin & Metastatic small cell lung cancer & DNA alkylating agent & $\begin{array}{l}\text { Grade } 3 \text { or } 4 \text { elevations in AST and ALT in } 3.5 \% \\
\text { and } 6.4 \% \text {, respectively }\end{array}$ \\
\hline Ozanimod & Relapsing multiple sclerosis & $\begin{array}{l}\text { Spingosine 1-phosphate } \\
\text { receptor modulator }\end{array}$ & $\begin{array}{l}\text { Grade } 3 \text { or } 4 \text { elevations in AST or ALT in } 1.1 \% \text { of } \\
\text { patients }\end{array}$ \\
\hline Pralsetinib & Non-small cell lung cancer & Kinase inhibitor & $\begin{array}{l}\text { Grade } 3 \text { or } 4 \text { elevations in AST and ALT in } 5.4 \% \\
\text { and } 6 \% \text {, respectively }\end{array}$ \\
\hline Remdesivir & COVID-19 & Antiviral drug & $\begin{array}{l}\text { Grade } 1 \text { and } 2 \text { elevations in AST or ALT seen } \\
\text { in healthy volunteers. Grade } 3 \text { and } 4 \text { eleva- } \\
\text { tions in AST or ALT have been seen in patients } \\
\text { with COVID-19 taking remdesivir, though the } \\
\text { incidence was similar between patients taking } \\
\text { placebo vs remdesivir }\end{array}$ \\
\hline Satralizumab & Neuromyelitis optica spectrum disorder & IL-6 signaling inhibition & $\begin{array}{l}\text { Elevations in AST or ALT }>3 \times \text { ULN occurred in } \\
3 \% \text { of patients }\end{array}$ \\
\hline Selpercatinib & Lung and thyroid cancer & Kinase inhibitor & $\begin{array}{l}\text { Grade } 3 \text { or } 4 \text { elevations in AST and ALT in } 8 \% \text { and } \\
9 \% \text {, respectively }\end{array}$ \\
\hline Tepotinib & Non-small cell lung cancer & Kinase inhibitor & $\begin{array}{l}\text { Grade } 3 \text { or } 4 \text { elevations in AST or ALT in } 4.2 \% \text { of } \\
\text { patients }\end{array}$ \\
\hline Tucatinib & HER2-positive breast cancer & Kinase inhibitor & $\begin{array}{l}\text { Grade } 3 \text { or } 4 \text { elevations in AST, ALT, and Tbili in } \\
6 \%, 8 \% \text {, and } 1.5 \% \text {,respectively }\end{array}$ \\
\hline Umbralisib & $\begin{array}{l}\text { Marginal zone lymphoma and follicular lym- } \\
\text { phoma }\end{array}$ & Kinase inhibitor & $\begin{array}{l}\text { Grade } 3 \text { or } 4 \text { elevations in AST and ALT in } 7 \% \text { and } \\
8 \% \text {, respectively }\end{array}$ \\
\hline
\end{tabular}

ALT alanine aminotransferase, AST aspartate aminotransferase, HIV human immunodeficiency virus, IL-6 interleukin-6, Tbili total bilirubin, $U L N$ upper limit of normal

${ }^{\text {a }}$ Defined as AST or ALT $\geq 5 \times$ ULN, or Tbili $\geq 3 \times$ ULN 
levels ( $>5 \times \mathrm{ULN}$ ) are found in $3-10 \%$ of patients taking lopinavir/ritonavir and the injury is often self-limited even with continuation of the drug [22]. Furthermore, use of this regimen has decreased over time given its lack of efficacy [23].

Remdesivir has increasingly been used in hospitalized patients as it has been shown to be superior to placebo in decreasing the time to recovery in hospitalized patients [24]. Various studies have reported elevations in serum aminotransferases in patients with COVID-19 treated with remdesivir with a range of $15-50 \%$ [25-27]. However, in controlled trials of hospitalized patients with COVID-19, laboratory markers of hepatotoxicity were similar compared to placebo $[24,28,29]$. There have been rare case reports of acute liver failure associated with remdesivir, but causality has been difficult to establish as most cases were associated with critically ill patients who also may have received other potentially hepatotoxic agents [30].

Tocilizumab, an anti-IL-6 receptor monoclonal antibody previously used in various rheumatologic conditions, has increasingly been used in the treatment of COVID-19 [31]. The first known case of tocilizumab-related DILI was described by Muhović et al., with a RUCAM score of 8 , suggestive of "probable" DILI [32]. Their patient developed peak AST of $1076 \mathrm{IU} / \mathrm{L}$ and ALT of $1541 \mathrm{IU} / \mathrm{L} 2$ days following tocilizumab administration. Ten days later, the patient had resolution of his liver chemistries.

\section{Updates in DILI Diagnosis and Causality Assessments}

The diagnosis of DILI remained a challenge in 2020. As there is still no single definitive biochemical test, DILI remains a diagnosis of exclusion. Causality assessment tools, such as RUCAM, have gained increasing acceptance as demonstrated by Teschke and Danan who found that RUCAM was used to assess possible cases of idiosyncratic DILI in more than 81,000 published reports and in more than 14,000 possible herbal induced liver injury (HILI) cases listed in PubMed since 1993 [33]. While RUCAM is an effective tool, it relies on a degree of expertise with DILI in order to best determine the scoring of its various elements. For example, one area of concern in the reliability of RUCAM is in patients with non-alcoholic fatty liver disease or other chronic liver diseases. Ghabril et al. from the US DILI Network analyzed 551 patients who were suspected of having DILI based on expert consensus and RUCAM scores, and stratified patients into three groups based on the presence of "no comorbidities (0)", "mild comorbidities (1-2)", or "significant comorbidities (>2)" [34]. The authors found that the mean RUCAM scores decreased with increasing comorbidities $(p<0.001)$. Furthermore, the probability of diagnosing DILI with a high level of confidence was significantly lower in patients with significant comorbidities compared with those with mild or no comorbidities ( $p<$ 0.001 ). The authors concluded that a higher comorbidity burden complicates the causality assessment of patients with suspected DILI, emphasizing the importance of discovering better diagnostic methods for DILI in such patients. Nevertheless, RUCAM is considered far superior to non-liverspecific tools such as the Naranjo score [35]. As a case in point, Mullins et al. evaluated the frequency and pattern of micafungin-induced DILI using both RUCAM and the Naranjo algorithm [36]. The authors included 47 possible cases over a 1-year period at a single center and the criteria for DILI was met in nine (19\%) patients, defined as ALT $\geq$ $5 \times$ ULN, alkaline phosphatase (ALP) $\geq 2 \times$ ULN, or total bilirubin $\geq 2 \times$ ULN with any change in ALT or ALP. There was agreement between the two causality assessment methods in only 4/9 (44\%) cases. Using RUCAM, five (10.6\%) cases met criteria for micafungin-induced DILI, indicating a prevalence of $10.6 \%$ in this population. In contrast, the Naranjo algorithm found nine (19\%) cases of suspected DILI, which was likely an overestimation [36].

Diagnosis of DILI remains a challenge in part because there are no clearly established metabolic risk factors for which patients will develop DILI. Teschke and Danan identified several potential risk factors for DILI in their review article [37]. Most notably, they reviewed a quantitative analysis of 3312 cases of DILI that were assessed for causality with RUCAM and noted that of the 36 most commonly implicated drugs, 22 drugs $(61.1 \%)$ were metabolized through cytochrome P450 (CYP) pathways, whereas 14 drugs (38.9\%) were metabolized via other pathways. The most commonly implicated CYP isoforms were CYP 3A4/5 (49.6\%), CYP 2C9 (24.6\%), CYP 2E1 (13.2\%), CYP 2C19 (7.3\%), CYP 1A2 (3.5\%), and CYP 2D6 (1.8\%). The authors note that other studies have suggested that specific isoforms including CYP 1A2, CYP 2C8/2C9, and CYP 3A5 have a higher likelihood of causing DILI, but the cases were not assessed for causality with RUCAM and some critical details were missing from some of the cases [37]. Therefore, more data are needed on the relationship of CYP metabolism of drugs and the risks for DILI to establish a better understanding of the various mechanisms of DILI.

\subsection{Novel Biomarkers and DILI}

\subsubsection{Genetic Biomarkers}

The hunt for a specific diagnostic DILI biomarker continued in 2020. Genetic polymorphisms remained of ongoing interest, particularly in relation to anti-tuberculosis liver injury (ATLI). $N$-Acetyltransferase 2 has been the focus of many ATLI studies over the past few decades. Several groups again 
demonstrated that "slow acetylator" phenotypes were associated with an increased risk of developing ATLI [38-40]. Unfortunately, most of these studies are limited by small sample sizes and lack ethnic diversity (as most studies were conducted among Asian or Latin American populations) and thus their generalizability to European and North American populations remains unclear.

Human leukocyte antigens (HLAs) are another area of research interest for predicting susceptibility to DILI and multiple polymorphisms for various drugs have been implicated. Tangamornsuksan et al. performed a large pooled meta-analysis of all available reports of HLA polymorphism studies associated with lapatinib, a chemotherapy medication used for HER2 + breast cancer, and found a clear association between HLA-DRB1*07:01 and lapatinib-induced hepatotoxicity (odds ratio 6.23) [41]. This study was unique in that the authors felt the data were strong enough to recommend genetic screening of HLA-DRB $1 * 07: 01$ in patients with breast cancer prior to lapatinib therapy. In contrast, data regarding other HLA markers are limited by low positive predictive values and the high cost to implement widespread screening, thus limiting their application in preventing DILI $[42,43]$.

\subsubsection{Serum Biomarkers}

The standard serum liver tests, including ALT, AST, ALP, and total bilirubin (Tbili) have been used to diagnosis and monitor DILI for decades, yet they lack specificity for hepatotoxicity and DILI. Therefore, there has been ongoing interest in discovering novel serum biomarkers that can (a) improve specificity for liver injury better than ALT; (b) reveal specific mechanisms of DILI; and (c) better prognosticate the severity of DILI [44]. Glutamate dehydrogenase (GLDH) has emerged as a promising liver-specific serum biomarker of hepatocellular injury. Schomaker et al. demonstrated its liver specificity in a study that compared ALT and GLDH levels in patients with Duchene muscular dystrophy with healthy controls to differentiate the effect of muscle injury or disease on aminotransferases from GLDH [45]. They found that serum ALT levels were increased 20-fold in patients with Duchene muscular dystrophy compared with controls, whereas serum GLDH levels were similar in patients with Duchene muscular dystrophy and healthy controls. The authors also describe a case of a patient with rhabdomyolysis who developed elevations in AST, ALT, and creatine kinase, while GLDH remained normal until the patient developed hypoxia-induced liver injury [45]. Roth et al. reviewed the literature on emerging serum biomarkers of DILI specifically, including GLDH [46]. They highlight the potential advantages of GLDH as a biomarker including no differences in levels based on age or gender, and little intra-subject and inter-subject individual variability in several studies. Some of the disadvantages of GLDH are that transient elevations of GLDH may occur in the context of common bile duct stone passage, circulatory disturbances leading to ischemic or congestive hepatopathy, and certain medication use such as cholestyramine that are not associated with clinically significant liver injury [46]. While GLDH represents a general marker of hepatotoxicity, it has also been proposed as a potential mechanistic biomarker. Glutamate dehydrogenase is located within the mitochondrial matrix of hepatocytes and thus it has been theorized that GLDH may be released early in DILI if the cause of hepatocyte death is mitotoxicity [47]. According to this hypothesis, hepatocyte death that does not involve primary mitochondrial injury would result in the release of intact mitochondria into the circulation. This then could be removed via centrifugation and result in lower GLDH activity. The authors tested this hypothesis by treating mice with either acetaminophen, which is a known mitochondrial toxicant, or furosemide, which causes hepatocyte death via other mechanisms. Surprisingly, GLDH levels were not affected by centrifugation in both the acetaminophen and furosemide groups. However, the ratio of GLDH:ALT was five-fold lower in the furosemide group compared with acetaminophen. Using electron microscopy, the authors confirmed that both treatments had resulted in mitochondrial injury. Interestingly, only the furosemide-treated group was found to have mitochondrial injury within vesicles, suggesting that mitophagia may account for the lower GLDH:ALT ratio seen in the furosemide group [47]. Another interesting study using GLDH was published by Llewellyn et al. in which the authors tested seven promising biomarkers and found that a three-biomarker combination of GLDH, K18, and miR122 had similar sensitivity and specificity for detecting liver injury compared to ALT in acetaminophen-treated patients with DILI, but lacked any superiority to ALT individually [48].

Acetaminophen-protein adducts represent N-acetyl-pbenzoquinone imine (NAPQI) covalently bound to cysteine groups on proteins that are released into blood during hepatocyte lysis. Prior studies have shown that these adducts can distinguish acetaminophen-related acute liver failure from other causes of acute liver failure [49-52]. This year, Chiew et al. analyzed 240 patients who presented with acetaminophen overdose and found that the initial acetaminophenprotein adduct concentration could predict which patients presenting with normal or moderately elevated ALT levels would later develop hepatotoxicity [53]. Indeed, the acetaminophen-protein adducts were felt to be superior to ALT and AST in this setting. This is particularly notable because acetaminophen-protein products accurately predicted hepatotoxicity regardless of the time of ingestion, which is a critical aspect of determining when to start treatment in overdose settings, which is often unknown at the time of hospital presentation. 


\section{Electronic Medical Record-Based DILI Algorithms}

Because of its varied clinical presentations, DILI is a difficult entity to study epidemiologically. Several articles appeared this year exploring the role of electronic medical record-based algorithms designed to identify DILI. YeboahKorang et al. published a study in which they searched an electronic medical record database at the University of Michigan Hospital between October 2015 and September 2018 for encounters with an International Classification of Diseases 10th Revision T code for drug toxicity and a K-71 code for toxic liver injury [54]. They assessed causality with a combination of expert opinion and RUCAM scoring. The authors included 182 cases of suspected DILI based on this algorithm and identified "probable" DILI in 121 patients, thus giving a positive predictive value of $66.5 \%$. In contrast, Kang et al. published a similar study where they searched an electronic medical record database at three centers in South Korea [55]. They used an algorithm that searched for patients with ALT $\leq 3 \times$ ULN and Tbili $\leq 2 \times$ ULN within $48 \mathrm{~h}$ of admission who then subsequently developed liver test abnormalities including ALT $\geq 3 \times$ ULN and Tbili $\geq 2 \times$ ULN or ALT $\geq 5 \times$ ULN at any point during the admission. The authors found 1100 cases of suspected DILI based on this algorithm, and after reviewing each case using RUCAM, 365 were included as at least "possible" causes of DILI, giving a positive predictive value of $33.1 \%$. Both these studies suffer from relatively low positive predictive values and suggest that improvements are needed in screening algorithms for DILI before they can be accurately employed in population research. Furthermore, they are dependent on accurate coding to be reliable indicators of DILI, which poses another significant limitation.

\section{Quantitative Systems Pharmacology and DILI}

Over the last year, there have been several advances in the way we can attempt to predict DILI. With the rise of organoid, three-dimensional tissue culture models, the toxicity of drugs on human hepatocytes can be tested directly, rather than relying on animal testing. Inventions such as the threedimensional "liver-on-a chip" and liver organoid-based toxicity screens both use hepatic pluripotent cells as the basis of testing for DILI directly rather than waiting on safety trials or post-market results [56]. These models can detect various phenotypes of liver injury and can detect species-specific hepatotoxicity when tested with offending agents. For example, hepatocyte organoids have been used to study Alagille syndrome, fatty liver disease, Wilson's disease, hepatitis
B viral infection, and cystic fibrosis while cholangiocyte organoids have been established to study conditions such as primary sclerosing cholangitis (SC) [57]. Some of these organoids recreate the three-dimensional architecture of human hepatocytes of cholangiocytes that more accurately predicts response to potential hepatotoxins than traditional two-dimensional (2D) models. Shinozawa et al. created a human liver organoid from ten different, pluripotent stem cell lines that contained polarized immature hepatocytes with a bile canaliculi-like architecture, establishing a unidirectional bile acid transport pathway [58]. The authors tested this organoid model against 238 marketed drugs and were able to predict hepatocyte viability and toxicity with a high sensitivity (88.7\%) and specificity (88.9\%). Furthermore, these systems may provide a way to more accurately predict liver toxicity and predict human relevance of hepatotoxicity detected in animal studies. For example, Mun et al. compared the toxic concentration of trovafloxacin, an antibiotic that was withdrawn from the market because of cases of acute liver failure, in traditional 2D cellular models vs organoid models [59]. They found that the organoid models induced hepatotoxicity at significantly lower concentrations of trovafloxacin doses compared with 2D models $(0.8-4 \mu \mathrm{M}$ vs $20-100 \mu \mathrm{M})$. Another application of organoid models was highlighted by Koido et al., in which they developed a polygenic risk score for DILI by aggregating the effects of numerous genome-wide loci identified from previous large genome-wide association studies [60]. The authors were able to predict susceptibility to DILI based on polygenic risk scores in human liver organoids and primary hepatocyte models in various drugs known to cause DILI including fasiglifam, amoxicillin-clavulanate, and flucloxacillin. This highlights the likely polygenic mechanisms underlying DILI susceptibility and is another area where organoid models may outperform traditional 2D cell culture models.

In 2020, the FDA renewed its annual license with the quantitative systems toxicology software called DILIsym [61]. Developed by an initiative started in 2011, DILIsym continues to be a resource for the FDA and pharmaceutical companies alike to assess the hepatic safety profile of new drug candidates [62]. Notably, the software was able to predict the safety profile for three potential migraine drug candidates. DILIsym successfully modeled the liver toxicity profiles of telcagepant and MK3207 and was also able to show the lower potential for hepatotoxicity with ubrogepant, an alternative migraine drug [63]. This ability to predict liver injury in drug development and also provide a better understanding of the mechanisms of DILI offers unique opportunities and promises in the hepatotoxicity field (Table 2). 


\section{Newly Described Hepatotoxins}

We identified only a few instances of DILI linked to new medications in 2020. Michels et al. described a case of DILI following administration of the biosimilar, glatiramer acetate medication "Clift" [64]. Glatiramer acetate is an immunomodulatory drug used in the long-term management of multiple sclerosis. In their case report, a 23-yearold female patient with multiple sclerosis initially developed mild-to-moderate increases in serum aminotransferases 4 weeks after treatment initiation. Therapy was paused but the patient continued to have massive elevations in laboratory values including AST $31.9 \times$ ULN, ALT $43.41 \times$ ULN, and GGT 5.35× ULN GGT, respectively. Liver biopsy was performed that revealed "slight fibrosis and multifocal microscopic necrotic areas predominantly in the centrilobular region, accompanied by lymphocyte infiltrates with an increased number of CD38-positive plasma cells". The patient remained asymptomatic and was treated with a course of oral steroids with resolution of laboratory values. A limitation of this case was the fact the authors did not use a causality assessment tool, raising the possibility of another etiology causing the liver injury, as the height of these liver tests makes them outliers when it comes to clinical trials. While glatiramer acetate has been used for over two decades in the management for multiple sclerosis, overt hepatotoxicity appears to be quite rare. In clinical trials, serum ALT elevations above $3 \times$ ULN were uncommon (reported in $7 \%$ of glatiramer recipients compared with $3 \%$ of placebo recipients) [65]. Moreover, in the GATE trial in 2017 that included 794 patients, there was no significance difference in hepatobiliary adverse events between the brand name product and biosimilar glatiramer acetate with an event rate that was extremely low for both groups (four total hepatobiliary adverse events) [66]. Despite this, suspected DILI in patients receiving glatiramer acetate biosimilars should be considered when using these new biosimilar agents [67].

Onasemnogene abeparvovec is a novel gene therapy medication recently approved by the FDA in 2019 for use in spinal muscular atrophy in children under 2 years old [68]. In a study by Chand et al., the authors evaluated five clinical trials to evaluate hepatic adverse events [69]. They found that $90 \%$ of patients had some degree of elevated liver enzymes; however, $61 \%$ of patients had liver enzyme elevations at baseline prior to treatment. Of note, liver enzyme abnormalities are common in patients with spinal muscular atrophy, and at least one third of autopsies on patients with spinal muscular atrophy have revealed steatosis [70]. In the Chand et al. cohort, two patients developed severe liver injury with predominantly hepatocellular injury where AST/ ALT were $>40 \times$ ULN. In both cases, liver biopsy exhibited inflammatory infiltrates composed of CD8+ T cells suggesting a possible immune-mediated injury. Both patients were treated with methylprednisolone and were discharged from the hospital within 2 weeks of the initial diagnosis [69].

Another newly identified drug implicated to cause hepatotoxicity is the antagonistic selective progesteronereceptor modulator, ulipristal acetate. While it was initially designed for one-time emergency contraception use, it has been approved for use for 3 months at a time for the treatment of uterine fibroids [71-73]. Several recent reports of

Table 2 DILIsym predictions for telcagepant, MK-3207, and ubrogepant in a simulated patient population of healthy volunteers [63]

\begin{tabular}{|c|c|c|c|}
\hline Compound & Dosing protocol & Simulated ALT $>3 \times$ ULN & Clinical ALT $>3 \times$ ULN \\
\hline \multirow[t]{2}{*}{ Telcagepant } & $280 \mathrm{mg}$ BID 12 weeks & $12.6 \%(36 / 285)$ & $3.2 \%(8 / 253)$ \\
\hline & 140 mg BID 12 weeks & $0 \%(0 / 285)$ & $1.9 \%(5 / 258)$ \\
\hline \multirow[t]{3}{*}{ MK-3207 } & $\begin{array}{l}200 \mathrm{mg} \text { q2h, } 2 \text { daily doses (400-mg daily dose), } \\
\text { for } 14 \text { days }\end{array}$ & $3.5 \%(10 / 285)$ & $\begin{array}{l}42 \%(5 / 12) \text { among individuals dosed for more than } \\
1 \text { week; most responding were given } 600-900 \\
\text { mg per day }\end{array}$ \\
\hline & $\begin{array}{l}300 \mathrm{mg} \text { q2h, } 2 \text { daily doses (600-mg daily dose), } \\
\text { for } 14 \text { days }\end{array}$ & $7 \%(20 / 285)$ & \\
\hline & $\begin{array}{l}450 \mathrm{mg} \text { q2h, } 2 \text { daily doses (900-mg daily dose), } \\
\text { for } 14 \text { days }\end{array}$ & $10.2 \%(29 / 285)$ & \\
\hline \multirow[t]{6}{*}{ Ubrogepant } & $100 \mathrm{mg} \mathrm{q} 2 \mathrm{~h}, 4$ days & $0 \%(0 / 285)$ & N/A \\
\hline & $1000 \mathrm{mg} \mathrm{q} 2 \mathrm{~h}, 4$ days & $0 \%(0 / 285)$ & N/A \\
\hline & 100 mg QD, 8 days & $0 \%(0 / 285)$ & N/A \\
\hline & 1000 mg QD, 8 days & $0 \%(0 / 285)$ & N/A \\
\hline & $\begin{array}{l}50 \mathrm{mg} \text { QD, } 2 \text { days on, } 2 \text { days off for } 56 \text { days, } 28 \\
\text { total doses }\end{array}$ & $0 \%(0 / 285)$ & N/A \\
\hline & $\begin{array}{l}100 \mathrm{mg} \text { QD, } 2 \text { days on, } 2 \text { days off for } 56 \text { days, } 28 \\
\text { total doses }\end{array}$ & $0 \%(0 / 285)$ & $0.8 \% 2 / 256$ \\
\hline
\end{tabular}

$A L T$ alanine aminotransferase, $B I D$ twice daily, $N / A$ not applicable, $q 2 h$ every 2 hours, $Q D$ once daily, $U L N$ upper limit of normal 
hepatotoxicity associated with longer term use in fibroid treatment were found. For example, Meunier et al. described a 58-year-old woman who developed fatigue, nausea, and abdominal discomfort followed by rising ALT/AST and international normalized ratio 2 months after beginning treatment with ulipristal acetate for symptomatic fibroids [74]. Over the following 3-4 weeks, the patient continued to decline and eventually developed subacute liver failure with a model for end-stage liver disease (MELD) of 36, requiring emergency liver transplantation. Liver biopsy of the explanted liver revealed cirrhosis and severe mediolobular and centrilobular necrosis associated with cholestasis and a massive polymorphous inflammatory cell infiltrate including lymphocytes, polynuclear neutrophils, eosinophils and Mallory bodies. The finding of cirrhosis on biopsy was unexpected given no history of chronic liver disease prior to hospitalization; however, ulipristal was considered causative based on the US DILIN method [74]. This case highlights that ulipristal or its metabolites may accumulate in a dose-dependent manner to cause hepatotoxicity, and caution is advised when prescribing the drug for longer durations. This is a similar scenario to that seen with bromfenac, a nonsteroidal anti-inflammatory drug originally investigated as a short-term pain reliever that was subsequently removed from the market after cases of severe hepatotoxicity were found in patients taking the medication for longer durations [75].

What appears to be the first case report of clinically apparent doxazosin-related DILI was published by Jiménez Sánchez et al. [76]. They described a 73-year-old male patient who presented with jaundice, choluria, pruritus, and nausea 35 days after starting treatment with doxazosin for benign prostatic hyperplasia. The patient was found to have AST $1211 \mathrm{IU} / \mathrm{L}$, ALT 1607 IU/L, ALP 514 IU/L, and Tbili $9.4 \mathrm{mg} / \mathrm{dL}$. The patient had gradual resolution of liver enzymes after drug discontinuation [76]. In this case, doxazosin was assigned a RUCAM score of "probable" despite the fact that prior clinical trial data showed low rates of serum aminotransferase elevations that were not significantly higher than with placebo [77].

Nonsteroidal anti-inflammatory drugs are another class of medication with widespread use that have increasingly been associated with hepatotoxicity. The overall incidence of nonsteroidal anti-inflammatory drug-induced DILI is low at $0.29-9$ cases $/ 100,000$ patient-years, but several case reports of fatal acute liver injury have appeared for various drugs in the class $[78,79]$. Pelubiprofen is a COX-2 selective nonsteroidal anti-inflammatory drugs that is primarily used in South Korea for the treatment of osteoarthritis and is touted for its lower incidence of gastrointestinal side effects [80]. Bak et al. reported a 29-year-old female patient who was hospitalized 2 days after ingesting pelibuprofen and found to have markedly elevated liver enzymes, including ALT $6479 \mathrm{IU} / \mathrm{L}$ and AST $4254 \mathrm{IU} / \mathrm{L}$ on day 2 of admission [81].
Interestingly, this patient had a Tbili of $3.12 \mathrm{mg} / \mathrm{dL}$ on the day of admission, which continued to uptrend to a peak of $11.81 \mathrm{mg} / \mathrm{dL}$ on day 23. Liver biopsy was performed on day 23 of admission and was consistent with cholestatic injury. The bilirubin levels remained elevated despite resolution of the serum aminotransferase elevations and a liver biopsy was repeated on day 124. It revealed chronic cholestatic hepatitis with absent bile ducts in more than $50 \%$ of the portal tracts. Immunostaining for CK19 confirmed bile duct loss and bile ductular proliferation. Therefore, a diagnosis of vanishing bile duct syndrome was made with a RUCAM score of 6 indicating a low "probable" causation by pelubiprofen, although the height of the aminotransferases is atypical of other cases of vanishing bile duct syndrome [81].

Liraglutide is a GLP-1 analog that acts to increase insulin secretion and has been used for the treatment of diabetes mellitus as well as a weight loss agent [82]. It has also recently been investigated as a potential treatment for nonalcoholic steatohepatitis [83]. The LEAD trial compared 48 weeks of subcutaneous liraglutide $(1.8 \mathrm{mg} /$ day $)$ to placebo in 52 patients with biopsy-proven non-alcoholic steatohepatitis and was shown to significantly improve steatosis and hepatocyte ballooning on biopsy [84]. The product label of liraglutide does not mention liver injury as an adverse event and only one case report of serious liver injury was reported with liraglutide, which presented as autoimmune hepatitis that did not improve with drug discontinuation [85]. Maor et al. reported a case of a 52-year-old female patient with obesity who was treated with liraglutide for weight loss for 3 months [86]. She presented to the hospital after 3 months of treatment because of abnormal liver tests and was found to have a mixed pattern of injury with ALT 547 IU/L, AST 268 IU/L, ALP 390 IU/L, GGT 427 IU/L, and Tbili $1.3 \mathrm{mg} /$ $\mathrm{dL}$. The patient had an abdominal ultrasound that revealed a fatty liver, and was diagnosed with DILI with a RUCAM score of 7 indicating "probable" DILI caused by liraglutide. The medication was discontinued, and the patient's liver enzymes gradually normalized over the next 3 months [86]. This positive dechallenge response with normalization of liver enzymes after cessation of liraglutide suggests its causative role in the liver injury.

\section{New Reports of Established Hepatotoxins}

\subsection{Anti-TB Drugs}

Anti-tuberculosis drug-induced liver injury continues to be a challenge in the management of tuberculosis (TB) and is a major reason for treatment discontinuation throughout the world. In particular, there has been extensive research conducted in Asian populations because of an observed high prevalence of ATLI, and the lack of a standardized 
biochemical monitoring strategy for ATLI. However, the Asian-Pacific Association for the Study of the Liver recently published guidelines recommending baseline laboratory and imaging testing for signs of pre-existing liver dysfunction prior to starting any TB treatment [87]. Interestingly, they recommend against routine hepatic biochemical monitoring after treatment has been initiated in patients without risk factors for ATLI, such as pre-existing liver disease or human immunodeficiency virus, or baseline laboratory abnormalities (grading of evidence A, grade of recommendation 1). The authors suggest monitoring these patients for clinical signs of ATLI while those with risk factors should have laboratory testing every 2 weeks for the first 8 weeks and then monthly [87]. While this strategy is likely the most cost effective, waiting until patients develop clinical symptoms will undoubtedly lead to some cases of ATLI being missed and potentially lead to poor patient outcomes, as has been previously reported [88].

Costs involved with the treatment and monitoring of adverse events are particularly important in lower income countries where resources are limited but the prevalence of TB is high. To combat this problem, Moed et al. designed a study using a simulated model of patient data from a village in Burundi that compared the sensitivity and cost effectiveness of monitoring for ATLI using ALT testing monthly vs point-of-care (POC) paper-based liver testing vs symptom monitoring alone [89]. Hepatotoxicity was defined as ALT $>$ $3 \times$ ULN with symptoms or ALT $>5 \times$ ULN without symptoms, and all patients were compared to gold standard testing with ALT. Based on the model, the POC paper-based test was found to be $56 \%$ more sensitive than symptom monitoring alone in detecting hepatotoxicity. Furthermore, gold standard ALT monitoring was only 5\% more sensitive for detecting hepatotoxicity compared with POC. As a result, the authors predicted that if the POC test could be made available at a cost of less than $\$ 1.60$, the POC test would be more cost effective than standard ALT laboratory testing [89].

Because of the inherent hepatotoxicity of many anti-TB drugs, clinicians have explored modified treatment regimens in an attempt to reduce adverse events. Isoniazid is a core component of the treatment regimen for both active and latent TB infection (LTBI) and is a well-known cause of ATLI [90]. Previously, the recommended treatment for LTBI was 9 months of isoniazid therapy in the USA and Canada, and 6-9 months in Europe. However, a recent clinical trial by Menzies et al. demonstrated comparable efficacy and fewer adverse events when comparing 4 months of rifampin vs 9 months of isoniazid therapy [91]. Therefore, Ronald et al. explored this further in 10,559 patients with LTBI (9684 given isoniazid and 875 received rifampin) in Quebec who were treated with either 9 months of isoniazid $(9 \mathrm{H})$ or 4 months of rifampin (4R) [92]. The authors found that the 4R group had higher rates of treatment completion $(53.5 \%$ vs $36.9 \%$, relative risk $(R R)=1.5)$, less severe hepatotoxicity ( $n=1$ vs $n=15$, odds ratio $=2.3$ ), and a lower average cost per patient (cost ratio $=0.7)$. Severe hepatotoxicity was defined as hospitalization with a diagnostic code indicating hepatotoxicity and subsequent drug discontinuation. While rifampin has its own risks of hepatotoxicity, this study suggests that the $4 \mathrm{R}$ regimen is associated with less hepatotoxicity, less cost, better completion rates, and similar efficacy and thus should be used as a first-line regimen in treating LTBI [92]. Both the Centers for Disease Control and Prevention and World Health Organization have updated their clinical practice guidelines to include $4 \mathrm{R}$ as a preferred regimen for the treatment of LTBI [93, 94].

Last, there continues to be extensive research into risk factors and biomarkers for ATLI, although no clear diagnostic or prognostic markers have yet been found. Udomsinprasert et al. explored the utility of leukocyte telomere length, a biological indicator of age-related diseases, as a potential diagnostic biomarker for ATLI [95]. They compared 100 healthy controls, 49 patients with TB with ATLI, and 53 patients with TB without ATLI using polymerase chain reaction analysis for leukocyte telomere length. They found that patients with TB collectively had shorter relative telomere length than healthy controls $(p=0.008)$. However, within the group of TB-infected patients, those with ATLI had significantly longer RTL than those without ATLI $(p=0.001)$ [95]. This is an interesting association and deserves further study to establish the exact relationship between leukocyte telomere length and ATLI and its role in clinical practice.

Tao et al. investigated the association of ABO blood groups with ATLI as a potential risk factor [96]. They compared ABO blood types in 146 ATLI cases vs 584 controls with ATLI defined as ALT $\geq 3 \times$ ULN, and/or ALP $\geq 2 \times$ ULN. Causality was assessed using RUCAM and highly probable, probable, or possible cases were included. Interestingly, patients with $\mathrm{A}, \mathrm{B}, \mathrm{AB}$, or non-O blood types all had an increased risk of developing ATLI ( $p=0.024$, $0.043,0.018$, and 0.010 respectively) compared with blood type $\mathrm{O}$. The authors theorize that this association between ATLI and ABO blood group determinants may be related to complement-mediated erythrocyte destruction through the Ii antigen system, especially in the case of rifampin, and deserves further study [96].

\subsection{Chemotherapy and DILI}

\subsubsection{ICls}

As noted above, a majority of newly approved medications are in the oncotherapeutic classes and often are associated with hepatotoxicity. Immune checkpoint inhibitors (ICIs) have been a cornerstone of treatment in a variety of 
previously difficult-to-treat cancers but are associated with a variety of immune-mediated adverse effects, including hepatotoxicity [97]. Guo et al. performed a large literature review of 20 clinical trials that evaluated PD-1/PD-L1 compared to traditional chemotherapy and found that PD-1/PD-L1 treatment was associated with increased risk of all-grade hepatitis $(\mathrm{RR}=5.85, p<0.01)$, and high-grade hepatitis ( $\mathrm{RR}$ $=5.66, p<0.01$ ) [98]. Various groups have reported the incidence and clinical signature of immune-mediated liver injury (ILICI) in the past year [99-105]. In one of the largest studies of 5762 patients from the MD Anderson Cancer Center who were treated with ICIs between 2010 and 2018, $100(2 \%)$ developed ILICI after a median latency of 59 days (range 8-454 days), which was defined as ALT $>5 \times$ ULN, in the absence of an alternate cause [99]. Immune-mediated liver injury was more common in patients treated with combination therapy of an anti-CTLA-4 and anti-PD-1 (9.2\%) compared with monotherapy with an anti-CTLA-4 (1.7\%) or anti-PD-1 (1.1\%). The majority of cases were hepatocellular in nature with a median value of ALT 482 IU in patients with liver metastases or underlying chronic liver disease compared with 563 IU without chronic liver disease. Median AST values were 445 IU and 416 IU, respectively, with only minimal elevations in alkaline phosphatase (194 IU and $169 \mathrm{IU})$. Median total bilirubin values were $1 \mathrm{mg}$ and $1 \mathrm{mg}$, respectively, but those patients with chronic liver disease or liver metastases had a broader range (up to $23 \mathrm{mg}$ vs $8 \mathrm{mg}$ ) [99].

Symptoms associated with ILICI were described in 164 patients with mostly melanoma from a multicenter study from Vanderbilt University Medical Center, Massachusetts General Hospital, Northwestern Memorial Hospital, Duke University Medical Center, Rutgers University Hospital, and the Melanoma Institute of Australia [100]. Nearly 75\% of the patients received a combination of ipilimumab and nivolumab or pembrolizumab and ILICI of CTCAE grade 2 was seen in $30.49 \%$, grade 3 in $45.73 \%$, and grade 4 toxicity in $14.02 \%$. Nearly half of patients had no symptoms (46.34\%); the most commonly reported symptoms were fatigue or anorexia (17.07\%), fever (14.02\%), nausea/vomiting (14.02\%), abdominal or back pain (11.59\%), arthralgias/ myalgias (8.54\%\%), and diarrhea (5.49\%) [100].

A majority of ILICI cases are hepatocellular, and histologically, anti-CTLA-4 agents have been associated with a form of granulomatous hepatitis and fibrin ring-type granulomas, along with central vein endotheliitis, while anti-PD-1 agents are associated with non-granulomatous forms of injury including zone 3 or panlobular inflammation and sinusoidal histiocytosis [106]. However, an increasing number of cases describing a form of immune-mediated SC have appeared [107-110]. Gudnason et al. reviewed available magnetic resonance cholangiopancreatography imaging from 25 patients in an unselected Icelandic DILI cohort and found that ten (40\%) of these patients had radiographic features of SC [111]. Similarly, the US DILIN published a study in which 4/56 (7\%) unselected patients with DILI with available adequate magnetic resonance cholangiopancreatography imaging showed SC changes [112]. Further research is needed into the true incidence of SC in DILI as these studies are limited by a small sample size and the availability of magnetic resonance cholangiopancreatography imaging. The pattern of injury seen with ILICI-related SC typically is cholestatic and presents with predominantly ALP elevations. A systematic review by Onoyama et al. of 31 cases of anti-PD-1-related cases of SC found that most occurred in patients with non-small cell lung cancer with a male predisposition of 2:1 and after a median number of 5.5 treatment cycles prior to the diagnosis (range 1-27) [113]. The cases were due to nivolumab in 19 patients; pembrolizumab in ten patients; and avelumab in one patient. Presenting symptoms were abdominal pain or discomfort in 35.5\%. On imaging, biliary tract dilation without obstruction was seen in $77 \%$; diffuse hypertrophy of the extrahepatic bile ducts in $90.5 \%$; and multiple strictures of intrahepatics in 30.4\% [113]. De Martin et al. describe the bile duct injury as being rich with $\mathrm{CD} 8+$ cytotoxic T-cell acute inflammatory infiltrates in SC cases seen with anti-CTLA-4 agents and more mixed CD8+/CD4+ T cells seen with anti-PD-1 agents [106]. These investigators have also described a form of destructive SC along with a granulomatous form of SC. Treatment of immune-mediated SC is unclear. One case involving bilobar intrahepatic bile duct stricturing and ectasia, with a portal-based mixed inflammation with minimal lobulitis, was responsive to a combination of steroids and ursodeoxycholic acid [114].

Risk factors associated with the development of ILICI were also a focus of several new reports this past year. The previously described risk of combination therapy was confirmed, along with a number of potential risk factors being added (see Table 3)

One of the most controversial areas in the management of patients with ILICI deals with the risk of restarting an ICI after ILICI resolves. While many societal and FDA guidelines call for the permanent discontinuation of ICI therapy for high-grade hepatotoxicity, many oncologists reported their willingness to resume treatment in select patients with grade 3 ILICI and in some cases, even grade 4 in the past year. $\mathrm{Li}$ et al. described the outcomes of 31 patients who were rechallenged out of a total of 102 patients with melanoma who had their treatment discontinued because of grade 3-4 ILICI [117]. Of these 31 patients, 25 (80.6\%) were able to successfully tolerate resumption of their ICIs and only six individuals had to have their rechallenge treatment discontinued. Risk factors for recurrent ILICI are difficult to assess given the small number of patients who had recurrent hepatitis; but interestingly, three of the six had an initial 
episode of ILICI that resolved without the need for steroids. The time to recurrence was 41 days. Liver metastases were present in three of six (vs six of 25 without recurrence), but the overall presence of any metastatic disease was not different between the groups [117]. A similar success rate of rechallenge was also reported by Patrinely Jr et al. with 39 of 66 cases $(62.12 \%)$ having no hepatitis, a recurrence rate of hepatitis in $25.76 \%$ (seen in a median time of 32 days), and the appearance of another form of immune-mediated adverse reaction (irAE) in 13.64\% [100]. Importantly, no deaths from recurrent hepatitis were reported. The rationale for rechallenge was provided as either disease progression off the ICI or lack of efficacy of a non-ICI treatment in more than $60 \%$ of rechallenge cases.

In a large, cross-sectional observational pharmacovigilance analysis of the WHO Vigibase, Dolladille et al. found 452 of 6123 irAEs were rechallenged with $29 \%$ having a recurrence of the initial irAE [118]. The number of patients being rechallenged for an initial irAE of hepatitis was 30\% (139 of 471), but the rate of recurrence of hepatitis after rechallenge was based on very small numbers where full data were available, with a range between $5.6 \%$ (for combination ICI therapy) and $14.3 \%$ (for retreatment with anti-CTLA-4).

Re-challenge with the combination of an anti-PD-1 agent and an anti-CTLA-4 agent carries a high risk of recurrence and is not recommended [119]. Interestingly, a report of antiPD-1 reintroduction in a patient with previous liver toxicity from anti-CTLA-4 led to fulminant hepatitis, whereas in contrast, a case series of re-challenge with an anti-PD-1 antibody in four patients out of 21 with previous liver toxicity from combination therapy did not lead to a recurrence of hepatitis $[114,120]$. Serra-Bellver et al. theorized that this was due to the extended half-life of anti-PD-1 drugs, whereby the reintroduction with anti-CTLA-4 monotherapy following anti-PD-1 liver toxicity can create a scenario as if the patient was receiving combination therapy [121].
Although the risk of ILICI might exist in patients with recurrent HCC or the development of other malignancies after a liver transplant, the high risk of graft rejection following the administration of ICIs contraindicates their use in such patients, as summarized by Kumar et al. [122]. Another area of focus when diagnosing ILICI is being able to distinguish between ICI-related DILI from idiopathic autoimmune hepatitis. De Martin et al. compared the salient features of both forms of liver injury as seen in Table 4 [106]. Idiopathic autoimmune hepatitis is more commonly seen in female patients and tends to be associated with autoimmune antibodies, while ILICI is less commonly associated with autoimmune antibodies. Histologically, ILICI is distinguished by the absence of plasmacytes, confluent necrosis, chronic hepatitis, and CD4+/CD20+ cells compared with idiopathic autoimmune hepatitis [106].

De Martin et al. also discuss the differences in management of ILICI compared with idiosyncratic DILI, noting that not all patients with ILICI will require corticosteroid treatment. They recommend that all patients who develop grade 3 hepatitis or higher should temporarily discontinue ICI therapy. Liver tests should be monitored over the next week and only if liver tests worsen should corticosteroid therapy be started, recognizing that many patients will have improvement in liver tests with ICI discontinuation alone [106]. However, these authors and others note that a subset of patients may develop refractory hepatitis despite ICI discontinuation and corticosteroid treatment, and the addition of another immunosuppressant agent, such as mycophenolate mofetil, may be required. [123-127].

\subsubsection{Tyrosine Kinase Inhibitors}

Tyrosine kinase inhibitors are another class of chemotherapeutic agents well known to cause hepatotoxicity. In a large literature review of all articles published in English from 2000 to 2018, Houron et al. evaluated 29 FDA-approved

Table 3 Potential risk factors for ILICI

\begin{tabular}{|c|c|c|}
\hline Risk factor & Authors & Comment \\
\hline NASH & Sawada et al. [115] & Among 35 patients with grade 2 or higher ILICI by Cox hazard analysis \\
\hline $\mathrm{HCC}$ & Sangro et al. [104] & May be explained by underlying metastatic liver disease \\
\hline $\begin{array}{l}\text { Statins }(4.7 \text {-fold) Younger age }(2.7- \\
\text { fold to } 4.9 \text {-fold) vs older age }(>70 \\
\text { years) } \\
\text { Male gender (1.6-fold) } \\
\text { Acetaminophen }(2.1 \text {-fold) }\end{array}$ & Cho et al. [116] & Korean study excluding HCC and elevated AST at baseline \\
\hline Liver metastases? & Li et al. [117] & Overall, metastatic disease not a risk factor \\
\hline $\begin{array}{l}\text { Rechallenge with combination ther- } \\
\text { apy of anti-CTLA- } 4 \text { and anti-PD1 }\end{array}$ & Miller et al. [99] & $\begin{array}{l}\text { Rate of ILICI in combination therapy of an anti-CTLA-4 and anti-PD-1 } \\
(9.2 \%) \text { compared with monotherapy with an anti-CTLA-4 (1.7\%) or } \\
\text { anti-PD-1 }(1.1 \%)\end{array}$ \\
\hline
\end{tabular}

AST aspartate aminotransferase, $H C C$ hepatocellular carcinoma, ILICI immune-mediated liver injury, NASH non-alcoholic steatohepatitis 
multi-kinase inhibitors used in clinical practice [128]. They noted that any aminotransferase elevation was exceedingly common, and that grade 3-4 hepatitis, defined as aminotransferase levels $>5 \times$ ULN, has been detected in 0-29\% of patients treated with tyrosine kinase inhibitors in clinical trials. The authors note that while most cases are asymptomatic and reversible, there is a $0.2-0.5 \%$ prevalence of acute liver failure related to afatinib, ceritinib, crizotinib, and regorafenib. Therefore, they recommend routine laboratory monitoring of ALT during treatment with tyrosine kinase inhibitors [128]. Liver test monitoring as part of a Risk Evaluation and Mitigation Strategy has been recommended for pexidartinib, a newly approved colony-stimulating factor-1 receptor inhibitor used in the management of patients with tenosynovial giant cell tumors [129]. While $95 \%$ of patients in the clinical trials experienced some hepatic adverse reaction, defined as any elevation of AST/ALT and/or ALP, the majority of abnormalities were low grade, dose dependent, and reversible isolated AST/ALT elevations and felt to be possibly related to colony-stimulating factor-1 receptor inhibition as a pharmacologic rather than a hepatotoxic effect. However, $4 \%$ (five of 140 patients) experienced a less common, but serious form of mixed or cholestatic injury that was associated with ductopenia or vanishing bile duct syndrome, that required up to 7 months before resolution. Additionally, in non-tenosynovial giant cell tumors patients with various malignancies, pexidartinib was associated with a form of mixed or cholestatic injury that was irreversible in a few cases and led to a liver transplant in one individual. As the elevations in liver tests in both forms of hepatic abnormalities were seen to occur within the first 8 weeks in nearly all cases, the Risk Evaluation and Mitigation Strategy program requires weekly liver test monitoring for the first 2 months in order to identify patients at risk as early as possible, in which case pexidartinib should be held or discontinued [129].

\subsubsection{Anti-estrogen/Progesterone Agents}

Various antineoplastic agents designed to antagonize estrogen or progesterone receptors are used to treat breast and gynecologic cancers. However, concerns about hepatotoxicity have limited the use of this class [130]. Onapristone is a progesterone receptor antagonist originally designed as a contraceptive agent and later used for metastatic breast cancer [131]. However, concerns about DILI related to its use led to its discontinuation from further development by the original sponsor [132]. In a recent study evaluating 88 patients from phase I-II studies who received twice-daily dosing of onapristone, the authors found elevations in AST/ ALT in $20.0 \%$ of subjects with known liver metastases, compared with only $6.0 \%$ for ALT and $9.5 \%$ for AST for patients without known liver metastases [133]. The one patient with a grade 3-4 ALT elevation and three of four patients with grade 3-4 AST elevations had liver metastases were assessed as being more likely related to liver metastases by the data review committee, rather than DILI. This

Table 4 Comparison of ILICI vs idiopathic autoimmune hepatitis [106]

\begin{tabular}{lll}
\hline & ILICI & Idiopathic AIH \\
\hline Gender preference & None & Female \\
ALT/AST elevation & Present & Present (20\% present as ALF) \\
ALP/GGT elevation & Can be present with cholangitis form & Seen with PBC/PSC overlap syndrome \\
Jaundice & Rare & variable \\
ANA & Seen in up to 50\% (speckled) & High titer, homogeneous pattern \\
ASMA & Possible (non-anti-F actin) & High titer anti-actin \\
Anti-LKM 1 & Negative & Positive (type II) \\
Serum IgG & Normal & Elevated \\
Histology & & Frequent \\
${ }^{\wedge}$ Plasmacytes & Absent or rare & Present \\
${ }^{\wedge}$ Portal inflammation & Present & Present \\
${ }^{\wedge}$ Confluent necrosis & Rare & Rare: look for overlap with PBC \\
${ }^{\wedge}$ Granulomas & Fibrin-ring type with CTLA-4 & Rare \\
${ }^{\wedge}$ Cholangitis & Present in destructive cholangitis form & Frequent \\
${ }^{\wedge}$ Chronic hepatitis/cirrhosis & Rare & Present \\
${ }^{\wedge}$ CD4+/CD20+ T cells & Rare & Rare \\
${ }^{\wedge}$ CD8+ T cells & Present &
\end{tabular}

$A I H$ autoimmune hepatitis, $A L F$ acute liver failure, $A L P$ alkaline phosphatase, $A N A$ antinuclear antibody, anti-LKM 1 anti-liver-kidney-microsomal antibody type 1, $A L F$ acute liver failure, $A L P$ alkaline phosphatase, $A N A$ antinuclear antibody, anti-LKM 1 anti-liver-kidney-microsomal antibody type 1, ASMA anti-smooth muscle antibody, GGT gamma-glutamyltransferase, ILICI immune-mediated liver injury, $P B C$ primary biliary cholangitis, $P S C$ primary sclerosing cholangitis 
causality was supported by the fact that onapristone was resumed at a lower dose without recurrence of liver injury, representing a negative re-challenge. While the sample size is small, this would suggest that onapristone-related DILI is less common than previously suggested. Therefore, it was concluded that further development and collection of safety data should continue in the planned phase II-III studies of onapristone in order to adequately characterize the hepatic safety profile [133].

\subsection{Inflammatory Bowel Disease Medications and DILI}

Barnhill et al. reviewed the spectrum of DILI seen with the different classes of agents used in inflammatory bowel disease [134]. The diagnosis of hepatotoxicity in this setting is challenging as patients can have alternative causes of liver disease such as primary SC that can confound the diagnosis of DILI. For example, in a study of 175 patients receiving infliximab, the authors found that 57 patients (33\%) had abnormal liver biochemistries. However, using RUCAM, they assessed only one case to be "highly probable", and ten others to be just "possibly" related [135]. This suggests that abnormal liver enzymes are common in patients with inflammatory bowel disease treated with infliximab, but that true DILI is rare. Similarly, Honap et al. reviewed 352 patients with inflammatory bowel disease treated with vedolizumab and found only five cases of suspected DILI using RUCAM [136]. The pattern of injury was predominantly cholestatic. Interestingly, one of the five patients had persistent cholestatic injury despite removal of the drug and was later diagnosed with primary SC [136].

\subsection{Antibiotics and DILI}

Antibiotics continue to be one of the most commonly implicated class of medications causing DILI and were the subject of many case reports this past year [137]. Following the FDA restrictions placed on telithromycin because of hepatotoxicity and other adverse effects, solithromycin was designed as an improved ketolide antibiotic with hopes for a lower incidence of hepatotoxicity [138]. However, the FDA determined that "solithromycin, which is $85 \%$ similar in structure to telithromycin, would be expected to have hepatotoxicity with its use." Although their Advisory Committee voted to approve the drug, the FDA requested safety data be collected from an additional 9000 patients. This added burden in terms of cost and time forced the sponsor, Cempra, to abandon any further trials with the drug [138]. Solithromycin was sold to Melinta Therapeutics who also decided not to pursue its further development, and its fate in the USA remains in limbo [139]. A pediatric communityacquired bacterial pneumonia trial that was well underway was also terminated simply because solithromycin cannot be approved for children without approval for use in adults. Cempra also licensed solithromycin to Toyama/Fujifilm who conducted its own phase III trials in Japan and submitted a new drug application to the Japanese regulatory authorities in 2019 [140].

\subsection{DOACs}

Direct-acting oral anticoagulants (DOACs) have become the mainstay in treatment of most conditions requiring therapeutic anticoagulation in the outpatient setting. However, prior case reports and clinical studies have suggested a small risk of hepatotoxicity [141]. Zhao et al. evaluated this risk with a large study of 13,698 patients prescribed either a DOAC or warfarin from 2010 to 2016 [142]. They found that 141 (2.1\%) of DOAC users and $232(3.4 \%)$ of warfarin users developed liver injury, defined as AST/ALT $>3 \times$ ULN or Tbili $>2 \times$ ULN. However, no causality assessment was reported, thus it is unclear what proportion of these cases represent true DILI [142]. In contrast, Björnsson et al. performed a similar population-based study of 15,819 patients who were prescribed DOACs in Iceland and found that 2300 (14.5\%) had elevated liver enzymes [143]. However, upon further review of these cases, the authors found only three patients had DILI based on RUCAM scoring. All three cases were related to rivaroxaban, giving an incidence of DILI with rivaroxaban of 1/1148 in this population [143]. Both of these studies concluded that DOACs are an extremely rare cause of DILI and their benefits likely outweigh their risks of hepatotoxicity.

\subsection{Antidepressants and Antipsychotics}

Psychotropic medications are among the most commonly prescribed drugs, but there is a paucity of understanding about their capacity to cause DILI [144]. Todorović Vukotić et al. reviewed the literature on antidepressant-related and antipsychotic-related DILI and unsurprisingly noted that nefazodone, phenelzine, imipramine, duloxetine, trazodone, chlorpromazine, and clozapine were the most implicated agents, as all have been previously described [145]. Various mechanisms and types of injury are involved, depending on the specific drug. However, a common risk factor appears to be polypharmacy, which increases the risk of drug-drug interactions and influences hepatic metabolism through various mechanisms, possibly increasing susceptibility to DILI [146]. An interesting case report was published by Khorassani et al. in which a 23 -year-old male patient with a history of schizophrenia was initiated on risperidone treatment at slowly increasing doses for acute psychosis [147]. The patient was noted to have a rise in ALT and AST from $25 \mathrm{U} / \mathrm{L}$ and $23 \mathrm{U} / \mathrm{L}$ on day 1 to $469 \mathrm{U} / \mathrm{L}$ and $125 \mathrm{U} / \mathrm{L}$, 
respectively, at day 13 . The patient was switched to oral paliperidone therapy and his liver enzymes declined over the next 5 days. The patient also received an intramuscular dose of paliperidone on day 16 to augment his anti-psychotic regimen. On day 22, the patient's liver function tests began to rise again, thus further doses of intramuscular and oral paliperidone were stopped and the patient was started on haloperidol, with normalization of liver function tests. Scoring of this case using the Naranjo scale indicated a probable association between risperidone use and hepatotoxicity (a score of 7) and with paliperidone use and hepatotoxicity (a score of 8) [147]. There have been no published reports of clinically apparent liver injury with symptoms or jaundice attributed to paliperidone therapy, and ALT elevations appear to be rare and mild.

\subsection{Acetaminophen}

Acetaminophen ingestion remains the number one cause of acute liver failure in the USA [148]. Mitchell et al. surveyed 765 patients to assess public knowledge of acetaminophen toxicity and found a significant minority (24\%) were unaware of the potential liver toxicity of acetaminophen, and knowledge of hepatotoxicity did not vary with education status [149]. Moreover, more than half of the respondents (58\%) did not know that extra-strength preparations of acetaminophen contained the same drug but in a different dose [149].

Hepatotoxicity from therapeutic doses of acetaminophen continue to appear. Lao et al. described a 30-year-old male patient with a history of Duchenne's muscular dystrophy who presented to a hospital for elective tracheostomy [150]. He received $14.5 \mathrm{~g}$ of acetaminophen over 4 days and developed acute liver failure and died 11 days after admission. Pharmacogenetic screening showed absent CYP2D6 metabolism and increased CYP1A2 activity, which may have increased the formation of NAPQI. He also had decreased function of UGT2B15, which increases the amount of acetaminophen available for metabolism to NAPQI. Having a reduced muscle mass and thus reduced glutathione levels to detoxify produced NAPQI may have also added to the risk of toxicity [150]. A second case involved a 9-year-old patient who took one 500-mg tablet every $4 \mathrm{~h}$ for four total doses to treat dental pain [151]. The child subsequently was brought into the hospital by her mother after developing abdominal pain, vomiting, headaches, and confusion. She was diagnosed with acute liver failure based on clinical and laboratory data. Liver biopsy revealed typical centrilobular necrosis seen with acetaminophen overdose as well as microvesicular steatosis in periportal hepatocytes, which is not typically seen in acetaminophen overdose. The patient died from multi-organ failure related to her acute liver failure. The authors theorized that the microvesicular steatosis seen in periportal hepatocytes in this patient suggests an increased vulnerability to acetaminophen hepatotoxicity via pre-existing mitochondrial dysfunction [151]. These cases emphasize that strict adherence to both dosage and frequency of medication administration is necessary as most patients' underlying liver function status is unknown.

\subsection{Miscellaneous Causes of DILI}

Bardoxolone methyl is an antioxidant inflammation modulator medication that activates the Nrf2 pathway and was designed to treat chronic kidney disease [152]. In a phase III trial of 2185 patients with stage 4 chronic kidney disease and type 2 diabetes, bardoxolone increased glomerular filtration rate but also lead to increases in AST/ALT and GGT. Enzyme elevations were maximal at week 4 and reversible, returning back to baseline after 48 weeks. No cases met Hy's law but two patients discontinued treatment after ALT rose $>10 \times$ ULN [152]. The authors noted that preclinical animal and cell culture experiments suggested that the increases in ALT and AST seen with bardoxolone methyl appear to be related to its pharmacological activity, as it significantly induced the messenger RNA expression of ALT and AST isoforms in cultured cells. Expression of ALT and AST isoforms in liver and kidney also positively correlated with Nrf2 status in mice. The authors felt that the increases in ALT and AST observed after bardoxolone treatment are at least partially related to the pharmacological induction of aminotransferases via Nrf2 activation, rather than to any intrinsic form of hepatotoxicity [153-157].

Metamizole is a common analgesic medication originally patented in 1922 that is frequently prescribed in areas such as Germany, Russia, and South America. It was taken off the market in the USA, UK, and Scandinavia because of adverse effects such as agranulocytosis [158]. Sebode et al. published an interesting case series on metamizole-induced DILI and suggested this is an underrecognized cause [159]. The authors analyzed 154 cases of DILI based on RUCAM scoring (median score 7, probable) at one hospital in Hamburg, Germany from 2008 to 2017. Of these, 23 (14.9\%) cases were attributed to metamizole. The injury pattern was predominantly hepatocellular. Of the 23 patients implicated, 17 patients underwent liver biopsy and $76.5 \%$ were found to have moderate-to-severe inflammatory histological activity while $35.3 \%$ had severe centrilobular necrosis $(>30 \%)$. Two cases progressed to acute liver failure and required liver transplantation. The authors concluded that metamizole is 
a frequent and underrated cause of DILI in areas where it is used [159]. However, despite being available for a century, it does not have hepatic adverse reactions mentioned on the European Medicines Agency drug label, thus one would question why we are just now seeing these reports. Björnsson reviewed the literature of metamizole and discovered approximately 17 other case reports of DILI with metamizole [160]. He notes that metamizole has the potential to cause DILI given that it is administered in a relatively high daily dose, has extensive hepatic metabolism, and its metabolites have relatively high lipophilicity. Further, he suggests metamizole may simply be a very rare cause of DILI whose use has seen an increase in popularity in certain countries such as Germany, to explain the increased number of cases [160]. Other recently published miscellaneous reports of DILI are found in Table 5.

\section{Updates in Treatment and Prevention}

Removal of the offending agent and supportive therapy are the mainstays of treatment for most cases of DILI [185]. Other than treatment with intravenous $\mathrm{N}$-acetylcysteine (NAC), there have been few other options for improving transplant-free survival in non-acetaminophen acute liver failure. There were several reports of the use of NAC to treat DILI published over the last year [186, 187]. Notably, we found a randomized controlled trial that evaluated the use of NAC for anti-TB-DILI [186]. Its results showed that although NAC did not shorten the time to ALT $<100 \mathrm{U} / \mathrm{L}$ in participants with anti-TB-DILI, it did significantly reduce the length of a hospital stay from 18 days to 9 days compared with placebo. A case report described using NAC to treat a 46-year-old female patient with non-small cell lung cancer who developed acute liver failure with a MELD of 39 while receiving crizotinib [187]. Her course improved after discontinuation of the chemotherapy and administration of NAC for 7 days. Such reports remain anecdotal and additional research is needed into how NAC may benefit non-acetaminophen-induced DILI.

A few studies in the past year have reviewed other potential therapies for DILI, including clausenamide (CLA) and licorice-derived $18 \beta$-glycyrrhetinic acid. An isolated compound from a popular fruit tree in southern China, CLA has previously been studied for its positive effects on hepatic glutathione synthesis [188]. A study exploring CLA and its effects on the liver described a mechanism of hepatic cell death called ferroptosis in addition to the classic mechanism of apoptosis in DILI [189]. Results of this study suggest that CLA protects against ferroptosis, which in turn protects against DILI. However, there is still much to be learned about the mechanism of ferroptosis and its implication on DILI in clinical practice. Licorice derivatives are often used to treat cases of suspected DILI in Japan, China, and other Asian countries. 18 $\beta$-Glycyrrhetinic acid, the main ingredient in licorice, is a staple of Chinese medicine, and is widely prescribed for its antioxidation, anti-inflammation, antiviral, and immune regulation properties [190]. Studies in mice and cells suggest that $18 \beta$-glycyrrhetinic acid has protective effects on the liver such as inhibition of hepatic fibrosis, attenuation of acute liver injury, reducing oxidative stress, and inflammation [191]. 18 $\beta$-Glycyrrhetinic acid has many similarities with steroid hormones, but because of its poor water solubility, its hepatoprotective effects are still limited to laboratory research.

\section{DILI Miscellany}

A few research papers propose new methods to predict the severity of DILI based on hepatocyte loss, and to predict hepatotoxicity in the preclinical drug screening phase of development. For example, Chung et al. designed a model that used DILIsym to estimate hepatocyte loss due to DILI in the setting of various patterns of ALT elevations [192]. The authors simulated four patterns of ALT during DILI: rapid onset and rapid decrease, moderate onset and moderate decrease, moderate onset and extended decrease $(>1$ month), and multiple peaks and increase and decrease in ALT. Using DILIsym, they found that the ranges of predicted hepatocyte loss for each pattern correlated independently with both peak ALT and the area under the curve (AUC) of serum ALT. However, when using a novel parameter $\mathrm{P}_{\mathrm{ALT}}$, that combined peak and $\mathrm{AUC}$ via the equation ALT_AUC*Peak $\mathrm{ALT}^{0.18} / 10^{5}((\mathrm{IU} / \mathrm{L}) 2 * \mathrm{~h})$, they were able to better predict hepatocyte loss across each of the time course than peak ALT or AUC alone [192]. While more research is needed into actual human application, this is unique as it may replace Hy's law as a more accurate means to predict the severity of DILI and the risk of acute liver failure.

Recently, the Council for International Organizations of Medical Sciences released a consensus statement on assessing and reporting DILI for healthcare professionals and drug developers [192]. It highlights multiple aspects of DILI, including definitions of DILI and its different phenotypes, causality assessment, evaluation of DILI risk in various stages of drug development, novel liver safety biomarkers, post-marketing liver safety surveillance, and a section on herbal and dietary supplement-related liver injury. Healthcare professionals, researchers, and drug developers alike should refer to this consensus statement as a foundational guideline as they continue to investigate DILI [193]. 
Table 5 Miscellaneous reports of drug-induced liver injury in established hepatotoxins

\begin{tabular}{|c|c|c|c|c|}
\hline Drug & Patient/study description & Injury pattern & Resolution with drug discontinuation? & Causality assessment \\
\hline \multicolumn{5}{|c|}{ Immune modulators } \\
\hline Natalizumab & 33-year-old female patient with MS [161] & Hepatocellular & Yes & None \\
\hline Teriflunomide & $\begin{array}{l}\text { 48-year-old patient with MS that resolved } \\
\text { after stopping the drug. Teriflunomide } \\
\text { has known hepatotoxicity in the drug } \\
\text { label since } 2012 \text { [162] }\end{array}$ & Mixed & Yes & RUCAM 8 \\
\hline \multicolumn{5}{|l|}{ Chemotherapy } \\
\hline Anastrazole & $\begin{array}{l}\text { 81-year-old female patient with breast } \\
\text { cancer and NAFLD [163] }\end{array}$ & Mixed & Yes & RUCAM 6 \\
\hline Capecitabine & $\begin{array}{l}\text { 63-year-old male patient with colon cancer } \\
\text { [164] }\end{array}$ & Mixed & Yes & None \\
\hline Fulvestrant & $\begin{array}{l}\text { 49-year-old female patient with metastatic } \\
\text { breast cancer [165] }\end{array}$ & Hepatocellular & Yes & None \\
\hline Gemcitabine & $\begin{array}{l}\text { 73-year-old male patient with urothelial } \\
\text { carcinoma [166] }\end{array}$ & Mixed & $\begin{array}{l}\text { Yes, also treated with levocetirizine and } \\
\text { dexamethasone }\end{array}$ & RUCAM 10 \\
\hline Nilotinib & $\begin{array}{l}\text { 24-year-old male patient with chronic } \\
\text { myeloid leukemia [167] }\end{array}$ & Cholestatic & $\begin{array}{l}\text { Yes, with dose reduction. Notably, patient } \\
\text { had a UGT1A1 mutation that may be } \\
\text { related to cholestatic liver injury }\end{array}$ & None \\
\hline Ribociclib & $\begin{array}{l}\text { 59-year-old female patient with metastatic } \\
\text { breast cancer [168] }\end{array}$ & Hepatocellular & $\begin{array}{l}\text { Yes. Also successfully rechallenged with } \\
\text { palbociclib, another CD } 4 / 6 \text { inhibitor } \\
\text { without recurrent hepatitis }\end{array}$ & None \\
\hline \multicolumn{5}{|l|}{ Antibiotics } \\
\hline Amoxicillin & $\begin{array}{l}\text { Two sisters, aged } 1 \text { and } 3 \text { years, presented } \\
2 \text { weeks after taking amoxicillin for an } \\
\text { upper respiratory infection [169] }\end{array}$ & Mixed & Yes & None \\
\hline Atovaquone & $\begin{array}{l}\text { 64-year-old female patient with ILD taking } \\
\text { atovaquone for Pneumocystis jirovecii } \\
\text { [170] }\end{array}$ & Hepatocellular & Yes & RUCAM 9 \\
\hline Ciprofloxacin & $\begin{array}{l}\text { 72-year-old male patient with pneumonia } \\
\text { [171] }\end{array}$ & Mixed & No, developed ALF and died & RUCAM 11 \\
\hline Flucloxacillin & $\begin{array}{l}\text { 74-year-old male patient with erysipelas } \\
\text { treated with flucloxacillin [172] }\end{array}$ & Mixed & Yes & RUCAM 8 \\
\hline Flucloxacillin & $\begin{array}{l}\text { 63-year-old female patient with cellulitis } \\
\text { treated with flucloxacillin [173] }\end{array}$ & Cholestatic & $\begin{array}{l}\text { No, developed VBDS requiring livertrans- } \\
\text { plantation }\end{array}$ & None \\
\hline Meropenem & $\begin{array}{l}\text { 83-year-old female patient who was treated } \\
\text { with meropenem for sepsis of unknown } \\
\text { etiology [174] }\end{array}$ & Mixed & Yes & None \\
\hline TMP-SMX & $\begin{array}{l}\text { Retrospective study of population of Euro- } \\
\text { pean American and African American } \\
\text { TMP-SMX DILI cases. Found that HLA } \\
\text { B*14:01 is associated with European } \\
\text { American cases and B*35:01 are associ- } \\
\text { ated with African American cases of } \\
\text { TMP-SMX DILI [175] }\end{array}$ & & & \\
\hline \multicolumn{5}{|c|}{ Anti-hypertensive agents } \\
\hline Amlodipine & 47-year-old male patient with HTN [176] & Mixed & Yes & RUCAM 6 \\
\hline Candesartan & $\begin{array}{l}\text { 55-year-old male patient with HTN and } \\
\text { chronic kidney disease V [177] }\end{array}$ & Cholestatic & Yes & RUCAM 8 \\
\hline Olmesartan & $\begin{array}{l}\text { 80-year-old female patient with HTN tak- } \\
\text { ing a combination olmesartan/amlodipine } \\
\text { pill [178] }\end{array}$ & Hepatocellular & Yes & None \\
\hline Olmesartan & 54-year-old female patient with HTN [179] & Hepatocellular & Yes & None \\
\hline $\begin{array}{l}\text { Lisinopril } \\
\text { Statins }\end{array}$ & 59-year-old female patient with HTN [180] & Cholestatic & No, patient died & None \\
\hline Atorvastatin & $\begin{array}{l}\text { 90-year-old female patient with history of } \\
\text { a TIA [181] }\end{array}$ & Hepatocellular & Yes & RUCAM 9 \\
\hline
\end{tabular}


Table 5 (continued)

\begin{tabular}{lllll}
\hline Drug & Patient/study description & Injury pattern & Resolution with drug discontinuation? & Causality assessment \\
\hline Fenofibrate & $\begin{array}{c}\text { 65-year-old male patient with hypertriglyc- } \\
\text { eridemia [182] }\end{array}$ & Hepatocellular & Yes & RUCAM 10 \\
Anti-arrhythmic agents & & & None \\
Amiodarone & $\begin{array}{c}\text { 67-year-old male patient who was treated } \\
\text { with IV amiodarone for atrial flutter [183] }\end{array}$ & Hepatocellular & Yes & \\
Anti-platelet & & & Yes & None \\
Clopidogrel & $\begin{array}{c}\text { 78-year-old male patient with a history of } \\
\text { an MI [184] }\end{array}$ & Mixed & & \\
\hline
\end{tabular}

$A L F$ acute liver failure, $H L A$ human leukocyte antigen, $H T N$ hypertension, $I V$ intravenous, $M I$ myocardial infarction, $M S$ multiple sclerosis, NAFLD non-alcoholic fatty live disease, RUCAM Roussel Uclaf Causality Assessment Method, TMP-SMX trimethoprim-sulfamethoxazole, $V B D S$ vanishing bile duct syndrome

\section{Conclusions}

Drug-induced liver injury continues to be an area of immense clinical and research interest and investigators substantially expanded our understanding of many aspects of DILI over the past year. COVID-19 infection has claimed much of the limelight as a cause of hepatic injury and as a potential confounder of DILI. A number of drugs used to treat COVID-19 have been suspected to cause DILI. However, it remains unclear if the virus itself is a true risk DILI factor. The diagnosis of DILI remains a challenge despite an extensive research effort to identify a potential biomarker. While RUCAM continues to expand as a causality assessment method, and despite recent updates for diagnosing both DILI and HILI, it is not without limitations and has not replaced expert opinion in many hepatology circles. Novel technologies, such as organoid culture systems and the use of PALT, offer the prospect of improving our ability to predict DILI preclinically and prognosticate its severity in the clinic. Glutamate dehydrogenase may be poised to be a more specific marker of liver injury compared with ALT. This year's literature review uncovered a few new causes of DILI from both newly approved drugs as well as from previously unrecognized agents. Immune-mediated liver injury from checkpoint inhibitors continues to dominate the literature pertaining to oncotherapeutic agents. Despite the admonition of many guidelines to permanently discontinue the use of ICIs after ILICI, many investigators have demonstrated that rechallenge after recovery from even serious hepatotoxicity is both possible but can also be well tolerated without recurrence. For patients with no other treatment options, such an approach can be life prolonging.

\section{Declarations}

Funding No sources of funding were used to assist in the preparation of this article.
Conflict of interest Joseph Clinton, Sara Kiparizoska, Soorya Aggarwal, Stephanie Woo, and William Davis have no conflicts of interest that are directly relevant to the content of this article. James H. Lewis has consulting agreements or serves on drug safety monitoring boards for Allergan, Akebia, Alexion, Athira, Boehringer Ingelheim, Cleveland Clinic, Daiichi Sankyo, F2G, Galectin, Innate, Intercept, Lipocine, Madrigal, Novartis, Orphazyme, Palladio, Pfizer, Reata, Sanofi, TPG, Tsumura, Vertex, Zydus, and BMS, but otherwise has no other conflicts of interest.

Ethics approval There was no need for ethical approval.

Consent to participate Not applicable.

Consent for publication Not applicable.

Avail ability of data and material Data sharing is not applicable to this article as no datasets were generated or analyzed during the current study.

Code availability Not applicable.

Author's contributions All authors contributed to the study conception and design and to revising it critically for content. All authors read and approved the final version.

\section{References}

1. Ke L, Lu C, Shen R, Lu T, Ma B, Hua Y. Knowledge mapping of drug-induced liver injury: a scientometric investigation (2010-2019). Front Pharmacol. 2020;11:842. https://doi.org/10. 3389/fphar.2020.00842.

2. Danan G, Teschke R. Roussel Uclaf Causality Assessment Method for drug-induced liver injury: present and future. Front Pharmacol. 2019;29(10):853.

3. Jothimani D, Venugopal R, Abedin MF, Kaliamoorthy I, Rela M. COVID-19 and the liver. J Hepatol. 2020;73(5):1231-40. https://doi.org/10.1016/j.jhep.2020.06.006 ((Epub 2020 Jun 15. PMID: 32553666; PMCID: PMC7295524)).

4. Rosenberg JJ, Higley C, Lewis JH. Selected highlights from the recent literature of newly reported herbal and dietary supplement-induced liver injury. Adv Res Gastroenterol Hepatol. 2020. https://doi.org/10.19080/ARGH.2020.15.555904.

5. Rosenberg JJ, Higley C, Shabazi S, Lewis JH. Selected highlights and controversies of drug-induced liver injury from 
the recent literature. World J Gastroenterol Hepatol Endosc. 2020;1(2):1-16.

6. Journal impact factor list. 2020. https://www.scopusjournals. com/2020/07/journal-impact-factor.html\#1. Accessed 25 Apr 2021.

7. Real M, Barnhill MS, Higley C, Rosenberg J, Lewis JH. Druginduced liver injury: highlights of the recent literature. Drug Saf. 2019;42(3):365-87. https://doi.org/10.1007/s40264-018-0743-2 (PMID: 30343418).

8. Barnhill MS, Real M, Lewis JH. Latest advances in diagnosing and predicting DILI: what was new in 2017? Expert Rev Gastroenterol Hepatol. 2018;12(10):1033-43. https://doi.org/10.1080/ 17474124.2018 .1512854 .

9. Novel drug approvals. 2021. https://www.fda.gov/drugs/newdrugs-fda-cders-new-molecular-entities-and-new-therapeuticbiological-products/novel-drug-approvals-2020. Accessed 26 Feb 2021.

10. Huang C, Wang Y, Li X, et al. Clinical features of patients infected with 2019 novel coronavirus in Wuhan, China. Lancet. 2020;395(10223):497-506.

11. Guan WJ, Ni ZY, Hu Y, China Medical Treatment Expert Group for COVID-19, et al. Clinical characteristics of coronavirus disease 2019 in China. N Engl J Med. 2020. https://doi.org/10.1056/ NEJMo.a2002032.

12. Zhang C, Shi L, Wang F-S. Liver injury in COVID-19: management and challenges. Lancet Gastroenterol Hepatol. 2020. https:// doi.org/10.1016/S2468-1253(20)30057-1.

13. Xu L, Liu J, Lu M, Yang D, Zheng X. Liver injury during highly pathogenic human coronavirus infections. Liver Int. 2020. https://doi.org/10.1111/liv.14435.

14. Saviano A, Wrensch F, Ghany MG, Baumert TF. Liver disease and COVID-19: from pathogenesis to clinical care. Hepatology. 2021. https://doi.org/10.1002/hep.31684.

15. Kuhn JH, Li W, Choe H, Farzan M. Angiotensin-converting enzyme 2: a functional receptor for SARS coronavirus. Cell Mol Life Sci. 2004;61:738-43. https://doi.org/10.1007/s00018-0044242-5 ((PMID: 15549175)).

16. Hamming I, Timens W, Bulthuis ML, Lely AT, Navis G, van Goor H. Tissue distribution of ACE2 protein, the functional receptor for SARS coronavirus: a first step in understanding SARS pathogenesis. J Pathol. 2004;203:631-7. https://doi.org/ 10.1002/path.1570 ((PMID: 15141377)).

17. Walls AC, Park YJ, Tortorici MA, Wall A, McGuire AT, Veesler D. Structure, function, and antigenicity of the SARS-CoV-2 spike glycoprotein. Cell. 2020;181:281-92.e6. https://doi.org/ 10.1016/j.cell.2020.02.058 ((PMID: 32155444)).

18. Chai X, Hu L, Zhang Y, et al. Specific ACE2 expression in cholangiocytes may cause liver damage after 2019-nCoV infection. bioRxiv; 2020.

19. Parohan M, Yaghoubi S, Seraji A. Liver injury is associated with severe coronavirus disease 2019 (COVID-19) infection: a systematic review and meta-analysis of retrospective studies. Hepatol Res. 2020;50(8):924-35. https://doi.org/10.1111/ hepr.13510 ((Epub 2020 Jun 25. PMID: 32386449; PMCID: PMC7273097)).

20. Mao R, Liang J, Shen J, Ghosh S, Zhu L-R, Yang H, et al. Implications of COVID-19 for patients with pre-existing digestive diseases. Lancet Gastroenterol Hepatol. 2020;5:425-7.

21. Cai Q, Huang D, Yu H, Zhu Z, Xia Z, Su Y, et al. COVID-19: abnormal liver function tests. J Hepatol. 2020;73(3):566-74. https://doi.org/10.1016/j.jhep.2020.04.006 ((Epub 2020 Apr 13. PMID: 32298767; PMCID: PMC7194951)).

22. Meraviglia P, Schiavini M, Castagna A, Viganò P, Bini T, Landonio S, et al. Lopinavir/ritonavir treatment in HIV antiretroviral-experienced patients: evaluation of risk factors for liver enzyme elevation. HIV Med. 2004;5(5):334-43. https://doi.org/ 10.1111/j.1468-1293.2004.00232.x (PMID: 15369508).

23. Cao B, Wang Y, Wen D, Liu W, Wang J, Fan G, et al. A trial of lopinavir-ritonavir in adults hospitalized with severe COVID-19. N Engl J Med. 2020;382(19):1787-99. https://doi.org/10.1056/ NEJMoa2001282 ((Epub 2020 Mar 18. PMID: 32187464; PMCID: PMC7121492)).

24. Beigel JH, Tomashek KM, Dodd LE, Mehta AK, Zingman BS, Kalil AC, ACTT-1 Study Group Members, et al. Remdesivir for the treatment of COVID-19: final report. N Engl J Med. 2020;383(19):1813-26. https://doi.org/10.1056/NEJMo a2007764 ((Epub 2020 Oct 8. PMID: 32445440; PMCID: PMC7262788)).

25. Jorgensen SCJ, Kebriaei R, Dresser LD. Remdesivir: review of pharmacology, pre-clinical data, and emerging clinical experience for COVID-19. Pharmacotherapy. 2020;40(7):659-71. https://doi.org/10.1002/phar.2429/.

26. Grein J, Ohmagari N, Shin D, Diaz G, Asperges E, Castagna A, et al. Compassionate use of remdesivir for patients with severe Covid-19. N Engl J Med. 2020;382(24):2327-36. https://doi. org/10.1056/NEJMoa2007016 ((Epub 2020 Apr 10. PMID: 32275812; PMCID: PMC7169476)).

27. Antinori S, Cossu MV, Ridolfo AL, Rech R, Bonazzetti C, Pagani $\mathrm{G}$, et al. Compassionate remdesivir treatment of severe COVID19 pneumonia in intensive care unit (ICU) and non-ICU patients: clinical outcome and differences in post-treatment hospitalisation status. Pharmacol Res. 2020;158: 104899. https://doi.org/ 10.1016/j.phrs.2020.104899 ((Epub 2020 May 11. PMID: 32407959; PMCID: PMC7212963)).

28. Wang Y, Zhang D, Du G, Du R, Zhao J, Jin Y, et al. Remdesivir in adults with severe COVID-19: a randomised, double-blind, placebo-controlled, multicentre trial. Lancet. 2020;395(10236):1569-78. https://doi.org/10.1016/S01406736(20)31022-9 ((Epub 2020 Apr 29. Erratum in: Lancet. 2020 May 30;395(10238):1694. PMID: 32423584; PMCID: PMC7190303)).

29. Spinner CD, Gottlieb RL, Criner GJ, Arribas López JR, Cattelan AM, Soriano Viladomiu A, GS-US-540-5774 Investigators, et al. Effect of remdesivir vs standard care on clinical status at 11 days in patients with moderate COVID-19: a randomized clinical trial. JAMA. 2020;324(11):1048-57. https://doi.org/10.1001/jama. 2020.16349 ((PMID: 32821939; PMCID: PMC7442954)).

30. Carothers C, Birrer K, Vo M. Acetylcysteine for the treatment of suspected remdesivir-associated acute liver failure in COVID19: a case series. Pharmacotherapy. 2020;40(11):1166-71. https://doi.org/10.1002/phar.2464 ((Epub 2020 Oct 27. PMID: 33006138; PMCID: PMC7537093)).

31. Stone JH, Frigault MJ, Serling-Boyd NJ, Fernandes AD, Harvey L, Foulkes AS, BACC Bay Tocilizumab Trial Investigators, et al. Efficacy of tocilizumab in patients hospitalized with COVID-19. N Engl J Med. 2020;383(24):2333-44. https://doi.org/10.1056/ NEJMoa2028836 ((Epub 2020 Oct 21. PMID: 33085857; PMCID: PMC7646626)).

32. Muhović D, Bojović J, Bulatović A, et al. First case of druginduced liver injury associated with the use of tocilizumab in a patient with COVID-19. Liver Int. 2020;40(8):1901-5. https:// doi.org/10.1111/liv.14516.

33. Teschke R, Danan G. Worldwide use of RUCAM for causality assessment in 81,856 idiosyncratic DILI and 14,029 HILI cases published 1993-mid 2020: a comprehensive analysis. Medicines (Basel). 2020;7(10):62. https://doi.org/10.3390/medicines7 100062 ((PMID:33003400; PMCID:PMC7600114)).

34. Ghabril M, Gu J, Yoder L, et al. Significant medical comorbidities are associated with lower causality scores in patients presenting with suspected drug-induced liver injury. Clin Transl 
Gastroenterol. 2020;11(4): e00141. https://doi.org/10.14309/ctg. 0000000000000141.

35. Naranjo CA, Busto U, Sellers EM, Sandor P, Ruiz I, Roberts EA, et al. A method for estimating the probability of adverse drug reactions. Clin Pharmacol Ther. 1981;30(2):239-45. https://doi. org/10.1038/clpt.1981.154 ((PMID: 7249508)).

36. Mullins C, Beaulac K, Sylvia L. Drug-induced liver injury (DILI) with micafungin: the importance of causality assessment. Ann Pharmacother. 2020;54(6):526-32. https://doi.org/10.1177/ 1060028019892587.

37. Teschke R, Danan G. Idiosyncratic drug induced liver injury, cytochrome P450, metabolic risk factors and lipophilicity: highlights and controversies. Int J Mol Sci. 2021;22(7):3441. https://doi.org/10.3390/ijms22073441 ((PMID:33810530; PMCID:PMC8037096)).

38. Araujo-Mariz C, Militãode Albuquerque MFP, Lopes EP, Ximenes RAA, Lacerda HR, Miranda-Filho DB, et al. Hepatotoxicity during TB treatment in people with HIV/AIDS related to NAT2 polymorphisms in Pernambuco, Northeast Brazil. Ann Hepatol. 2020;19(2):153-60. https://doi.org/10.1016/j.aohep. 2019.09.008 (Epub 2019 Oct 24. PMID: 31734174).

39. Zhang D, Hao J, Hou R, Yu Y, Hu B, Wei L. The role of NAT2 polymorphism and methylation in anti-tuberculosis drug-induced liver injury in Mongolian tuberculosis patients. J Clin Pharm Ther. 2020;45:561-9. https://doi.org/10.1111/jcpt.13097.

40. Nicoletti P, Devarbhavi H, Goel A, Venkatesan R, Eapen CE, Grove JI, et al. Genetic risk factors in drug-induced liver injury due to isoniazid-containing antituberculosis drug regimens. Clin Pharmacol Ther. 2020. https://doi.org/10.1002/cpt.2100 ((Epub ahead of print. PMID: 33135175 ))

41. Tangamornsuksan W, Kongkaew C, Scholfield CN, et al. HLADRB 1*07:01 and lapatinib-induced hepatotoxicity: a systematic review and meta-analysis. Pharmacogenom J. 2020;20:47-56. https://doi.org/10.1038/s41397-019-0092-2.

42. Stephens C, Andrade RJ. Genetic predisposition to drug-induced liver injury. Clin Liver Dis. 2020;24(1):11-23. https://doi.org/10. 1016/j.cld.2019.08.003 (Epub 2019 Oct 31 PMID: 31753244).

43. Garcia-Cortes M, Robles-Diaz M, Stephens C, et al. Drug induced liver injury: an update. Arch Toxicol. 2020;94:3381407. https://doi.org/10.1007/s00204-020-02885-1.

44. Fu S, Wu D, Jiang W, Li J, Long J, Jia C. Molecular biomarkers in drug-induced liver injury: challenges and future perspectives. Front Pharmacol. 2020;10:1667. https://doi.org/10.3389/fphar. 2019.01667.

45. Schomaker S, Potter D, Warner R, Larkindale J, King N, Porter AC, et al. Serum glutamate dehydrogenase activity enables early detection of liver injury in subjects with underlying muscle impairments. PLoS ONE. 2020;15(5): e0229753. https:// doi.org/10.1371/journal.pone.0229753 ((PMID:32407333; PMCID:PMC7224523)).

46. Roth SE, Avigan MI, Bourdet D, Brott D, Church R, Dash A, et al. Next-generation DILI biomarkers: prioritization of biomarkers for qualification and best practices for biospecimen collection in drug development. Clin Pharmacol Ther. 2020;107(2):333-46. https://doi.org/10.1002/cpt.1571 ((Epub 2019 Sep 14. PMID: 31314926; PMCID: PMC7006882)).

47. Church RJ, Schomaker SJ, Eaddy JS, Boucher GG, Kreeger $\mathrm{JM}$, Aubrecht J, et al. Glutamate dehydrogenase as a biomarker for mitotoxicity; insights from furosemide hepatotoxicity in the mouse. PLoS ONE. 2020;15(10): e0240562. https:// doi.org/10.1371/journal.pone.0240562 ((PMID:33035276; PMCID:PMC7546462))

48. Llewellyn HP, Vaidya VS, Wang Z, Peng Q, Hyde C, Potter D, et al. Evaluating the sensitivity and specificity of promising circulating biomarkers to diagnose liver injury in humans. Toxicol
Sci. 2021. https://doi.org/10.1093/toxsci/kfab003 ((Epub ahead of print. PMID: 33483742))

49. Davern TJ II, James LP, Hinson JA, Polson J, Larson AM, Fontana RJ, et al. Measurement of serum acetaminophen protein adducts in patients with acute liver failure. Gastroenterology. 2006;130(3):687-94.

50. James LP, Capparelli EV, Simpson PM, Letzig L, Roberts D, Hinson JA, et al. Acetaminophen-associated hepatic injury: evaluation of acetaminophen protein adducts in children and adolescents with acetaminophen overdose. Clin Pharmacol Ther. 2008;84(6):684-90.

51. James LP, Letzig L, Simpson PM, Capparelli E, Roberts DW, Hinson JA, et al. Pharmacokinetics of acetaminophen-protein adducts in adults with acetaminophen overdose and acute liver failure. Drug Metab Dispos. 2009;37(8):1779-84.

52. Khandelwal N, James LP, Sanders C, Larson AM, Lee WM. Unrecognized acetaminophen toxicity as a cause of indeterminate acute liver failure. Hepatology. 2011;53(2):567-76.

53. Chiew AL, James LP, Isbister GK, Pickering JW, McArdle K, Chan $\mathrm{BSH}$, et al. Early acetaminophen-protein adducts predict hepatotoxicity following overdose (ATOM-5). J Hepatol. 2020;72(3):450-62. https://doi.org/10.1016/j.jhep.2019.10.030 ((Epub 2019 Nov 22 PMID: 31760072)).

54. Yeboah-Korang A, Louissaint J, Tsung I, et al. Utility of a computerized ICD-10 algorithm to identify idiosyncratic drug-induced liver injury cases in the electronic medical record. Drug Saf. 2020;43:371-7. https://doi.org/10.1007/ s40264-019-00903-5.

55. Kang Y, Kim SH, Park SY, Park BY, Lee JH, An J, et al. Evaluation of drug-induced liver injury developed during hospitalization using electronic health record (I)-based algorithm. Allergy Asthma Immunol Res. 2020;12(3):430-42. https:// doi.org/10.4168/aair.2020.12.3.430 ((PMID:32141257; PMCID:PMC7061161)).

56. Jang KJ, Otieno MA, Ronxhi J, et al. Reproducing human and cross-species drug toxicities using a liver-chip. Sci Transl Med. 2019;11(517):eaax5516. https://doi.org/10.1126/scitranslmed. aax5516.

57. Shiota J, Samuelson LC, Razumilava N. Hepatobiliary organoids and their applications for studies of liver health and disease: are we there yet? Hepatology. 2021. https://doi.org/10.1002/hep. 31772 ((Epub ahead of print. PMID: 33638203)).

58. Shinozawa $T$, et al. High-fidelity drug-induced liver injury screen using human pluripotent stem cell-derived organoids. Gastroenterology. 2021. https://doi.org/10.1053/j.gastro.2020.10.002.

59. Mun SJ, Ryu JS, Lee MO, Son YS, Oh SJ, Cho HS, et al. Generation of expandable human pluripotent stem cell-derived hepatocyte-like liver organoids. J Hepatol. 2019;71(5):970-85. https:// doi.org/10.1016/j.jhep.2019.06.030 ((Epub 2019 Jul 9 PMID: 31299272)).

60. Koido M, Kawakami E, Fukumura J, Noguchi Y, Ohori M, Nio $\mathrm{Y}$, et al. Polygenic architecture informs potential vulnerability to drug-induced liver injury. Nat Med. 2020;26(10):1541-8. https:// doi.org/10.1038/s41591-020-1023-0 ((Epub 2020 Sep 7 PMID: 32895570)).

61. U.S. FDA renews annual DILIsym software licenses. Business Wire. 2020. http://ww.businesswire.com/news/home/20200 506005345/en/U.S.-FDA-Renews-Annual-DILIsym-SoftwareLicenses. Accessed 13 Aug 2021.

62. DILIsym ${ }^{\circledR}$ : drug-induced liver injury (DILI) modeling software. Simulations Plus. 2021. http://ww.simulations-plus.com/softw are/dilisym/. Accessed 13 Aug 2021.

63. Smith B, Rowe J, Watkins PB, Ashina M, Woodhead JL, Sistare FD, et al. Mechanistic investigations support liver safety of ubrogepant. Toxicol Sci. 2020;177(1):84-9. https://doi.org/10. 1093/toxsci/kfaa093. 
64. Michels S, Zizer E, Barth TF, Wassner A, Fangerau T, Taranu $\mathrm{D}$, et al. Drug-induced liver injury associated with the biosimilar glatiramer acetate $\left(\mathrm{Clift}^{\circledR}\right)$. Mult Scler Relat Disord. 2020;40: 101948. https://doi.org/10.1016/j.msard.2020.101948 ((Epub 2020 Jan 13 PMID: 31972518))

65. Fox RJ, Miller DH, Phillips JT, Hutchinson M, Havrdova E, Kita M, CONFIRM Study Investigators, et al. Placebo-controlled phase 3 study of oral BG-12 or glatiramer in multiple sclerosis. N Engl J Med. 2012;367(12):1087-97. https://doi.org/10. 1056/NEJMoa1206328 ((Erratum in: N Engl J Med. 2012 Oct 25;367(17):1673. PMID: 22992072)).

66. Cohen J, Belova A, Selmaj K, et al. Equivalence of generic glatiramer acetate in multiple sclerosis: a randomized clinical trial. JAMA Neurol. 2015;72(12):1433-41. https://doi.org/10.1001/ jamaneurol.2015.2154.

67. Sabatino JJ, Mehta NJ, Kakar S, Zamvil SS, Cree BAC. Acute liver injury in a Glatopa-treated patient with MS. Neurol Neuroimmunol Neuroinflamm. 2017;4(4): e368. https://doi.org/10. 1212/NXI.0000000000000368.

68. U.S. National Library of Medicine, National Institutes of Health. DailyM-d-Zolgensma: onasemnogene abeparvovec-xioi kit. https://dailymed.nlm.nih.gov/dailymed/lookup.cfm?setid=68cd4 f06-70e1-40d8-bedb-609ec0afa471. Accessed 13 Aug 2021.

69. Chand D, Mohr F, McMillan H, Tukov FF, Montgomery K, Kleyn A, et al. Hepatotoxicity following administration of onasemnogene abeparvovec (AVXS-101) for the treatment of spinal muscular atrophy. J Hepatol. 2020. https://doi.org/10. 1016/j.jhep.2020.11.001 ((S0168-8278(20)33748-X, Epub ahead of print. PMID: 33186633)).

70. Crawford TO, Sladky JT, Hurko O, Besner-Johnston A, Kelley RI. Abnormal fatty acid metabolism in childhood spinal muscular atrophy. Ann Neurol. 1999;45(3):337-43. https://doi.org/10. 1002/1531-8249(199903)45:3\%3c337::aid-ana9\%3e3.0.co;2-u ((PMID: 10072048)).

71. Jadav SP, Parmar DM. Ulipristal acetate, a progesterone receptor modulator for emergency contraception. J Pharmacol Pharmacother. 2012;3(2):109-11. https://doi.org/10.4103/0976-500X. 95504.

72. Piecak K, Milart P, Woźniakowska E, Paszkowski T. Ulipristal acetate as a treatment option for uterine fibroids. Prz Menopauzalny. 2017;16(4):133-6. https://doi.org/10.5114/pm.2017. 72792 .

73. Woodhead N, Pounds R, Irani S, Pradhan P. Ulipristal acetate for uterine fibroids: 2 years of real world experience in a UK hospital. J Obstet Gynaecol. 2018;38(6):813-7. https://doi.org/ 10.1080/01443615.2017.1405926 ((Epub 2018 Mar 12 PMID: 29526144)).

74. Meunier L, Meszaros M, Pageaux GP, Delay JM, Herrero A, Pinzani V, et al. Acute liver failure requiring transplantation caused by ulipristal acetate. Clin Res Hepatol Gastroenterol. 2020;44(3):e45-9. https://doi.org/10.1016/j.clinre.2020.02.008 ((Epub 2020 Mar 4 PMID: 32146092)).

75. Moses PL, Schroeder B, Alkhatib O, Ferrentino N, Suppan T, Lidofsky SD. Severe hepatotoxicity associated with bromfenac sodium. Am J Gastroenterol. 1999;94(5):1393-6. https://doi.org/ 10.1111/j.1572-0241.1999.01093.x ((PMID: 10235225)).

76. Jiménez Sánchez J, Serrano Díaz L, Martínez Crespo JJ. Acute hepatocellular drug-induced liver injury probably caused by doxazosin. Rev Esp Enferm Dig. 2020. https://doi.org/10.17235/ reed.2020.7268/2020.

77. Ceral J, Solar M. Doxazosin: safety and efficacy in the treatment of resistant arterial hypertension. Blood Press. 2009;18(12):74-7. https://doi.org/10.1080/08037050902843726 ((PMID: 19353415)).

78. Björnsson ES. Hepatotoxicity by drugs: the most common implicated agents. Int J Mol Sci. 2016;17:224.
79. Lewis JH, Stine JG. Nonsteroidal anti-inflammatory drugs and leukotriene receptor antagonists: pathology and clinical presentation of hepatotoxicity. In: Kaplowitz N, DeLeve LD, editors. Drug-induced liver disease. 3rd ed. Amsterdam: Elsevier; 2013. p. $370-402$.

80. Shin JY, Chang MJ, Kim MK, Kang S-B, Kim K-I, Park HG, et al. Efficacy and safety of short-term use of a pelubiprofen $\mathrm{CR}$ and aceclofenac in patients with symptomatic knee osteoarthritis: a double-blinded, randomized, multicenter, active drug comparative, parallel-group, phase IV, non-inferiority clinical trial. PLoS ONE. 2020;15(9): e0238024. https://doi.org/10.1371/ journal.pone. 0238024 .

81. Bak H, Kim H, Lee S, Lee Y, Bang SM, Lee YS. A case of vanishing bile duct syndrome after drug-induced liver injury caused by pelubiprofen. Yonsei Med J. 2020;61(12):1060-3. https:// doi.org/10.3349/ymj.2020.61.12.1060 ((PMID:33251781; PMCID:PMC7700876))

82. Mehta A, Marso SP, Neeland IJ. Liraglutide for weight management: a critical review of the evidence. Obes Sci Pract. 2017;3(1):3-14. https://doi.org/10.1002/osp4.84 ((Epub 2016 Dec 19. PMID: 28392927; PMCID: PMC5358074)).

83. Armstrong MJ, Barton D, Gaunt P, et al. Liraglutide efficacy and action in non-alcoholic steatohepatitis (LEAN): study protocol for a phase II multicentre, double-blindeandomizedsed, controlled trial. BMJ Open. 2013;3: e003995. https://doi.org/ 10.1136/bmjopen-2013-003995.

84. Armstrong MJ, Houlihan DD, Rowe IA, Clausen WH, Elbrønd B, Gough SC, et al. Safety and efficacy of liraglutide in patients with type 2 diabetes and elevated liver enzymes: individual patient data meta-analysis of the LEAD program. Aliment Pharmacol Ther. 2013;37(2):234-42. https://doi.org/10.1111/apt.12149 ((Epub 2012 Nov 19 PMID: 23163663)).

85. Kern E, Van Wagner LB, Yang GY, Rinella ME. Liraglutide-induced autoimmune hepatitis. JAMA Intern Med. 2014;174(6):984-7. https://doi.org/10.1001/jamainternmed. 2014.674

86. Maor Y, Ergaz D, Malnick SDH, Melzer E, Neuman MG. Liraglutide-induced hepatotoxicity. Biomedicines. 2021;9(2):106. https://doi.org/10.3390/biomedicines9020106.

87. Devarbhavi H, Aithal G, Treeprasertsuk S, Takikawa H, Mao Y, Shasthry SM, Asia Pacific Association of Study of Liver, et al. Drug-induced liver injury: Asia Pacific Association of Study of Liver consensus guidelines. Hepatol Int. 2021. https://doi.org/ 10.1007/s12072-021-10144-3 ((Epub ahead of print. PMID: 33641080)).

88. Hayashi PH, Fontana RJ, Chalasani NP, et al. Under-reporting and poor adherence to monitoring guidelines for severe cases of isoniazid hepatotoxicity. Clin Gastroenterol Hepatol. 2015;13(9):1676-82.e1. https://doi.org/10.1016/j.cgh.2015.02. 024.

89. Moed S, Suprenant M, Odjidja EN, Meguid T, Zaman MH. Economic evaluation of screening interventions for drug induced liver injury. Clin Infect Dis. 2020. https://doi.org/10.1093/cid/ ciaa1347 ((Epub ahead of print. PMID: 32898262)).

90. Metushi I, Uetrecht J, Phillips E. Mechanism of isoniazidinduced hepatotoxicity: then and now. Br J Clin Pharmacol. 2016;81(6):1030-6. https://doi.org/10.1111/bcp.12885.

91. Menzies D, Adjobimey M, Ruslami R, Trajman A, Sow O, Kim $\mathrm{H}$, et al. Four months of rifampin or nine months of isoniazid for latent tuberculosis in adults. N Engl J Med. 2018;379(5):440-53. https://doi.org/10.1056/NEJMoa1714283 ((PMID: 30067931)).

92. Ronald LA, FitzGerald JM, Bartlett-Esquilant G, et al. Treatment with isoniazid or rifampin for latent tuberculosis infection: population-based study of hepatotoxicity, completion, and costs. Eur Respir J. 2020. https://doi.org/10.1183/13993003.02048-2019. 
93. Sterling TR, Njie G, Zenner D, et al. Guidelines for the treatment of latent tuberculosis infection: recommendations from the National Tuberculosis Controllers Association and CDC, 2020. MMWR Recomm Rep. 2020;69(No. RR-1):1-11. https://doi.org/ 10.15585/mmwr.rr6901a1.

94. Guidelines on the management of latent tuberculosis infection. https://www.who.int/tb/publications/latent-tuberculosis-infec tion/en/. Accessed 13 Aug 2021.

95. Udomsinprasert W, Chanhom N, Suvichapanich S, et al. Leukocyte telomere length as a diagnostic biomarker for anti-tuberculosis drug-induced liver injury. Sci Rep. 2020;10:5628. https:// doi.org/10.1038/s41598-020-62635-2.

96. Tao B, Yang M, Chen H, Pan H, Liu W, Yi H, et al. Association of $\mathrm{ABO}$ blood group and antituberculosis drug-induced liver injury: a case-control study from a Chinese Han population. J Clin Pharm Ther. 2020;45(4):638-45. https://doi.org/10.1111/ jcpt.13139 ((Epub 2020 Apr 7 PMID: 32259340)).

97. Peeraphatdit TB, Wang J, Odenwald MA, Hu S, Hart J, Charlton MR. Hepatotoxicity from immune checkpoint inhibitors: a systematic review and management recommendation. Hepatology. 2020;72(1):315-29. https://doi.org/10.1002/hep.31227 ((PMID: 32167613))

98. Guo X, Li W, Hu J, Zhu EC, Su Q. Hepatotoxicity in patients with solid tumors treated with PD-1/PD-L1 inhibitors alone, PD-1/PD-L1 inhibitors plus chemotherapy, or chemotherapy alone: systematic review and meta-analysis. Eur J Clin Pharmacol. 2020;76(10):1345-54. https://doi.org/10.1007/s00228020-02903-2 ((Epub 2020 Jun 8. PMID: 32507925; PMCID: PMC7481165)).

99. Miller ED, Abu-Sbeih H, Styskel B, Nogueras Gonzalez GM, Blechacz B, Naing A, et al. Clinical characteristics and adverse impact of hepatotoxicity due to immune checkpoint inhibitors. Am J Gastroenterol. 2020;115(2):251-61. https://doi.org/10. 14309/ajg.0000000000000398 ((PMID: 31789632)).

100. Patrinely JR Jr, McGuigan B, Chandra S, Fenton SE, Chowdhary A, Kennedy LB, et al. A multicenter characterization of hepatitis associated with immune checkpoint inhibitors. Oncoimmunology. 2021;10(1):1875639. https://doi.org/10.1080/2162402X. 2021.1875639 ((PMID:33628621; PMCID:PMC7889227)).

101. Ramos-Casals M, Brahmer JR, Callahan MK, Flores-Chávez A, Keegan N, Khamashta MA, et al. Immune-related adverse events of checkpoint inhibitors. Nat Rev Dis Prim. 2020;6(1):38. https:// doi.org/10.1038/s41572-020-0160-6 ((PMID: 32382051)).

102. Yang H, Yao Z, Zhou X, Zhang W, Zhang X, Zhang F. Immunerelated adverse events of checkpoint inhibitors: insights into immunological dysregulation. Clin Immunol. 2020;213: 108377. https://doi.org/10.1016/j.clim.2020.108377 ((Epub 2020 Mar 2 PMID: 32135278)).

103. Riveiro-Barciela M, Barreira-Díaz A, Vidal-González J, MuñozCouselo E, Martínez-Valle F, Viladomiu L, et al. Immune-related hepatitis related to checkpoint inhibitors: clinical and prognostic factors. Liver Int. 2020;40(8):1906-16. https://doi.org/10.1111/ liv.14489 ((Epub 2020 Jun 3 PMID: 32329119)).

104. Sangro B, Chan SL, Meyer T, Reig M, El-Khoueiry A, Galle PR. Diagnosis and management of toxicities of immune checkpoint inhibitors in hepatocellular carcinoma. J Hepatol. 2020;72(2):320-41. https://doi.org/10.1016/j.jhep.2019.10.021 ((PMID:31954495; PMCID:PMC7779342)).

105. Suo A, Chan Y, Beaulieu C, Kong S, Cheung WY, Monzon $\mathrm{JG}$, et al. Anti-PD1-induced immune-related adverse events and survival outcomes in advanced melanoma. Oncologist. 2020;25(5):438-46. https://doi.org/10.1634/theoncologist. 2019-0674 ((Epub 2020 Feb 12. PMID: 32048768; PMCID: PMC7216458)).

106. De Martin E, Michot JM, Rosmorduc O, Guettier C, Samuel D. Liver toxicity as a limiting factor to the increasing use of immune checkpoint inhibitors. JHEP Rep. 2020;2(6): 100170. https://doi. org/10.1016/j.jhepr.2020.100170.

107. De Martin E, Michot JM, Papouin B, Champiat S, Mateus C, Lambotte $\mathrm{O}$, et al. Characterization of liver injury induced by cancer immunotherapy using immune checkpoint inhibitors. J Hepatol. 2018;68(6):1181-90. https://doi.org/10.1016/j.jhep. 2018.01.033 ((Epub 2018 Feb 8 PMID: 29427729)).

108. Kleiner DE, Berman D. Pathologic changes in ipilimumabrelated hepatitis in patients with metastatic melanoma. Dig Dis Sci. 2012;57(8):2233-40. https://doi.org/10.1007/s10620-0122140-5 ((Epub 2012 Mar 21. PMID: 22434096; PMCID: PMC3792485))

109. Nabeshima S, Yamasaki M, Matsumoto N, Takaki S, Nishi Y, Kawamoto K, et al. Atezolizumab-induced sclerosing cholangitis in a patient with lung cancer: a case report. Cancer Treat Res Commun. 2021;26: 100270. https://doi.org/10.1016/j.ctarc.2020. 100270 ((Epub 2020 Dec 10 PMID: 33338849)).

110. McClure T, Cui W, Asadi K, John T, Testro A. Case of nivolumab-induced sclerosing cholangitis: lessons from long-term follow-up. BMJ Open Gastroenterol. 2020;7(1): e000487. https://doi.org/10.1136/bmjgast-2020-000487 ((PMID:32912846; PMCID:PMC7484867)).

111. Gudnason HO, Björnsson HK, Gardarsdottir M, Thorisson HM, Olafsson S, Bergmann OM, et al. Secondary sclerosing cholangitis in patients with drug-induced liver injury. Dig Liver Dis. 2015;47(6):502-7. https://doi.org/10.1016/j.dld.2015.03.002 ((Epub 2015 Mar 11 PMID: 25840876)).

112. Ahmad J, Rossi S, Rodgers SK, Ghabril M, Fontana RJ, Stolz A, et al. Sclerosing cholangitis-like changes on magnetic resonance cholangiography in patients with drug induced liver injury. Clin Gastroenterol Hepatol. 2019;17(4):789-90. https://doi.org/10. 1016/j.cgh.2018.06.035

113. Onoyama T, Takeda Y, Yamashita T, Hamamoto W, Sakamoto $\mathrm{Y}$, Koda H, et al. Programmed cell death-1 inhibitor-related sclerosing cholangitis: a systematic review. World J Gastroenterol. 2020;26(3):353-65. https://doi.org/10.3748/wjg.v26.i3.353 ((PMID:31988594; PMCID:PMC6969883)).

114. Cheung V, Gupta T, Payne M, Middleton MR, Collier JD, Simmons A, et al. Immunotherapy-related hepatitis: real-world experience from a tertiary centre. Frontline Gastroenterol. 2019;10(4):364-71. https://doi.org/10.1136/flgastro-2018101146 ((Epub 2019 Mar 22. PMID: 31656561; PMCID: PMC6788136))

115. Sawada K, Hayashi H, Nakajima S, Hasebe T, Fujiya M, Okumura T. Non-alcoholic fatty liver disease is a potential risk factor for liver injury caused by immune checkpoint inhibitor. J Gastroenterol Hepatol. 2020;35(6):1042-8. https://doi.org/10.1111/ jgh.14889 ((Epub 2019 Nov 21 PMID: 31752049)).

116. Cho YA, Han JM, Kang SY, Kim DC, Youn YJ, Choi KH, et al. Analysis of risk factors for hepatotoxicity induced by immune checkpoint inhibitors. J Immunother. 2021;44(1):16-21. https:// doi.org/10.1097/CJI.0000000000000347 ((PMID: 33290362)).

117. Li M, Sack JS, Rahma OE, Hodi FS, Zucker SD, Grover S. Outcomes after resumption of immune checkpoint inhibitor therapy after high-grade immune-mediated hepatitis. Cancer. 2020;126(23):5088-97. https://doi.org/10.1002/cncr. 33165 ((Epub 2020 Sep 5. PMID: 32888341; PMCID: PMC7655516)).

118. Dolladille C, Ederhy S, Sassier M, Cautela J, Thuny F, Cohen $\mathrm{AA}$, et al. Immune checkpoint inhibitor rechallenge after immune-related adverse events in patients with cancer. JAMA Oncol. 2020;6(6):865-71. https://doi.org/10.1001/jamaoncol. 2020.0726 ((PMID:32297899; PMCID:PMC7163782)).

119. Spain L, Walls G, Messiou C, Turajlic S, Gore M, Larkin J. Efficacy and toxicity of rechallenge with combination immune checkpoint blockade in metastatic melanoma: a case series. 
Cancer Immunol Immunother. 2017;66(1):113-7. https://doi. org/10.1007/s00262-016-1926-2 ((Epub 2016 Nov 12 PMID: 27838762))

120. Riveiro-Barciela M, Muñoz-Couselo E, Fernandez-Sojo J, Diaz-Mejia N, Parra-López R, Buti M. Acute liver failure due to immune-mediated hepatitis successfully managed with plasma exchange: new settings call for new treatment strategies? J Hepatol. 2019;70(3):564-6. https://doi.org/10.1016/j.jhep.2018.10. 020 ((Epub 2018 Nov 28 PMID: 30503040)).

121. Serra-Bellver P, Valpione S, Lorigan P. Sequential immunotherapy regimens-expect the unexpected. Lancet Oncol. 2016;17(7):854-5. https://doi.org/10.1016/S1470-2045(16) 30198-X ((Epub 2016 Jun 4 PMID: 27269742)).

122. Kumar V, Shinagare AB, Rennke HG, Ghai S, Lorch JH, Ott PA, et al. The safety and efficacy of checkpoint inhibitors in transplant recipients: a case series and systematic review of literature. Oncologist. 2020;25(6):505-14. https://doi.org/10.1634/theon cologist.2019-0659 ((Epub 2020 Feb 11. PMID: 32043699; PMCID: PMC7288631)).

123. Tanaka R, Fujisawa Y, Sae I, Maruyama H, Ito S, Hasegawa N, et al. Severe hepatitis arising from ipilimumab administration, following melanoma treatment with nivolumab. Jpn J Clin Oncol. 2017;47(2):175-8. https://doi.org/10.1093/jjco/hyw167 ((PMID: 28173241))

124. Spänkuch I, Gassenmaier M, Tampouri I, Noor S, Forschner A, Garbe C, et al. Severe hepatitis under combined immunotherapy: resolution under corticosteroids plus anti-thymocyte immunoglobulins. Eur J Cancer. 2017;81:203-5. https://doi.org/ 10.1016/j.ejca.2017.05.018 ((Epub 2017 Jun 20. Erratum in: Eur J Cancer. 2017 Dec;87:221. PMID: 28641200)).

125. McGuire HM, Shklovskaya E, Edwards J, Trevillian PR, McCaughan GW, Bertolino P, et al. Anti-PD-1-induced highgrade hepatitis associated with corticosteroid-resistant $\mathrm{T}$ cells: a case report. Cancer Immunol Immunother. 2018;67(4):563-73. https://doi.org/10.1007/s00262-017-2107-7 ((Epub 2017 Dec 30. PMID: 29289977; PMCID: PMC5860100))

126. Pollack MH, Betof A, Dearden H, Rapazzo K, Valentine I, Brohl AS, et al. Safety of resuming anti-PD-1 in patients with immune-related adverse events (irAEs) during combined antiCTLA-4 and anti-PD1 in metastatic melanoma. Ann Oncol. 2018;29(1):250-5. https://doi.org/10.1093/annonc/mdx642 ((PMID:29045547; PMCID:PMC5834131)).

127. Kopecký J, Kubecek O, Geryk T, Podhola M, Ziaran M, Priester $\mathrm{P}$, et al. Hepatic injury induced by a single dose of nivolumab: a case report and literature review. Klin Onkol. 2019;32(2):133-8. https://doi.org/10.14735/amko2019133 ((PMID: 30995854)).

128. Houron C, Danielou M, Mir O, Fromenty B, Perlemuter G, Voican CS. Multikinase inhibitor-induced liver injury in patients with cancer: a review for clinicians. Crit Rev Oncol Hematol. 2020;21(157): 103127. https://doi.org/10.1016/j.critrevonc.2020. 103127 ((Epub ahead of print. PMID: 33161366)).

129. Lewis JH, Gelderblom H, van de Sande M, Stacchiotti S, Healey $\mathrm{JH}$, Tap WD, et al. Pexidartinib long-term hepatic safety profile in patients with tenosynovial giant cell tumors. Oncologist. 2020. https://doi.org/10.1002/onco.13629 ((Epub ahead of print. PMID: 33289960))

130. Chitturi S, Farrell GC. Estrogen receptor antagonists. Adverse effects of hormones and hormone antagonists on the liver. In: Kaplowitz N, DeLeve LD, editors. Drug-induced liver disease. 3rd ed. Amsterdam: Elsevier; 2013. pp. 610-2.

131. Robertson JF, Willsher PC, Winterbottom L, Blamey RW, Thorpe $\mathrm{S}$. Onapristone, a progesterone receptor antagonist, as first-line therapy in primary breast cancer. Eur J Cancer. 1999;35(2):2148. https://doi.org/10.1016/s0959-8049(98)00388-8 ((PMID: 10448262))
132. Jonat $\mathrm{W}$, Bachelot $\mathrm{T}$, Ruhstaller T, Kuss I, Reimann U, Robertson JFR. Randomized phase II study of lonaprisan as second-line therapy for progesterone receptor-positive breast cancer. Ann Oncol. 2013;24(10):2543-8. https://doi.org/10.1093/annonc/ mdt216 ((Epub 2013 Jun 20 PMID: 23788750)).

133. Lewis JH, Cottu PH, Lehr M, Dick E, Shearer T, Rencher W, et al. Onapristone extended release: safety evaluation from phase I-II studies with an emphasis on hepatotoxicity. Drug Saf. 2020;43(10):1045-55. https://doi.org/10.1007/s40264-02000964-x ((PMID:32594454; PMCID:PMC7497701)).

134. Barnhill MS, Steinberg JM, Jennings JJ, Lewis JH. Hepatotoxicty of agents used in the management of inflammatory bowel disease: a 2020 update. Curr Gastroenterol Rep. 2020;22(9):47. https:// doi.org/10.1007/s11894-020-00781-3 ((PMID: 32671616)).

135. Worland T, Chin KL, van Langenberg D, Garg M, Nicoll A. Retrospective study of idiosyncratic drug-induced liver injury from infliximab in an inflammatory bowel disease cohort: the IDLE study. Ann Gastroenterol. 2020;33(2):162-9. https://doi. org/10.20524/aog.2020.0453.

136. Honap S, Sticova E, Theocharidou E, Berry P, Irving PM, Samaan MA, et al. Vedolizumab-associated drug-induced liver injury: a case series. Inflamm Bowel Dis. 2021;27(3):e32-4. https://doi.org/10.1093/ibd/izaa286 ((PMID: 33155638)).

137. Björnsson ES. Drug-induced liver injury due to antibiotics. Scand J Gastroenterol. 2017;52(6-7):617-23. https://doi.org/ 10.1080/00365521.2017.1291719 ((Epub 2017 Feb 20. PMID: 28276834)).

138. Fernandes P, Pereira D, Watkins PB, Bertrand D. Differentiating the pharmacodynamics and toxicology of macrolide and ketolide antibiotics. J Med Chem. 2020;63(12):6462-73. https://doi.org/ 10.1021/acs.jmedchem.9b01159 ((Epub 2019 Nov 7 PMID: 31644280)).

139. Cempra withdraws solithromycin marketing authorization application in Europe. (2017, March 28). Melinta Therapeutics, Inc. 2017. https://ir.melinta.com/news-releases/news-release-details/ cempra-withdraws-solithromycin-marketing-authorization\#print. Accessed 13 Aug 2021.

140. Application for manufacturing and sales approval in Japan filed for T-4288, an antibacterial agent I FUJIFILM Toyama Chemical Co., Ltd. What's new. http://fftc.fujifilm.co.jp/en/news/news1 90425e.html. Accessed 13 Aug 2021.

141. Liakoni E, Rätz Bravo AE, Krähenbühl S. Hepatotoxicity of new oral anticoagulants (NOACs). Drug Saf. 2015;38(8):71120. https://doi.org/10.1007/s40264-015-0317-5 ((PMID: 26138527)).

142. Zhao J, Blais JE, Chui CSL, Suh IH, Chen EYH, Seto WK, et al. Association between nonvitamin $\mathrm{K}$ antagonist oral anticoagulants or warfarin and liver injury: a cohort study. Am J Gastroenterol. 2020;115(9):1513-24. https://doi.org/10.14309/ajg.00000 00000000678 ((PMID: 32467502)).

143. Björnsson HK, Gudmundsson DO, Björnsson ES. Liver injury caused by oral anticoagulants: a population-based retrospective cohort study. Liver Int. 2020;40:1895-900. https://doi.org/10. 1111/liv.14559.

144. Voican CS, Corruble E, Naveau S, Perlemuter G. Antidepressantinduced liver injury: a review for clinicians. Am J Psychiatry. 2014;171(4):404-15. https://doi.org/10.1176/appi.ajp.2013. 13050709 ((PMID: 24362450)).

145. Todorović Vukotić N, Đorđević J, Pejić S, Đorđević N, Pajović SB. Antidepressants- and antipsychotics-induced hepatotoxicity. Arch Toxicol. 2021. https://doi.org/10.1007/ s00204-020-02963-4.

146. Herrlinger C, Klotz U. Drug metabolism and drug interactions in the elderly. Best Pract Res Clin Gastroenterol. 2001;15(6):897918. https://doi.org/10.1053/bega.2001.0249 ((PMID: 11866484)). 
147. Khorassani F, Sousonis F, Lopez LV. Risperidone- and paliperidone-induced hepatotoxicity: case report and review of literature. Am J Health Syst Pharm. 2020. https://doi.org/10.1093/ ajhp/zxaa224 ((Epub ahead of print. PMID: 32699878)).

148. Shah NJ, Royer A, John S. Acute liver failure. Updated 2020 Nov 20. In: StatPearls. Treasure Island (FL): StatPearls Publishing; 2021.

149. Mitchell RA, Rathi S, Dahiya M, Zhu J, Hussaini T, Yoshida EM. Public awareness of acetaminophen and risks of drug induced liver injury: results of a large outpatient clinic survey. PLoS ONE. 2020;15(3): e0229070. https://doi.org/10.1371/journal. pone.0229070 ((PMID:32130228; PMCID:PMC7055817)).

150. Lao YE, Molden E, Kringen MK, Annexstad EJ, Saeverud HA, Jacobsen D, et al. Fatal liver failure after therapeutic doses of paracetamol in a patient with Duchenne muscular dystrophy and atypical pharmacogenetic profile of drug-metabolizing enzymes. Basic Clin Pharmacol Toxicol. 2020;127(1):47-51. https://doi. org/10.1111/bcpt.13389 ((Epub 2020 Feb 5 PMID: 31977139)).

151. Bouvet R, Cauchois A, Baert A, Fromenty B, Morel I, et al. Fatal acetaminophen poisoning with hepatic microvesicular steatosis in a child after repeated administration of therapeutic doses. Forensic Sci Int. 2020;310: 110258. https://doi.org/10.1016/j. forsciint.2020.110258

152. Lewis JH, Jadoul M, Block GA, Chin MP, Ferguson DA, Goldsberry A, et al. Effects of bardoxolone methyl on hepatic enzymes in patients with type 2 diabetes mellitus and stage 4 CKD. Clin Transl Sci. 2021;14(1):299-309. https://doi.org/10. 1111/cts.12868 ((Epub 2020 Sep 3. PMID: 32860734; PMCID: PMC7877861)).

153. Sporn MB, Liby KT, Yore MM, Fu L, Lopchuk JM, Gribble GW. New synthetic triterpenoids: potent agents for prevention and treatment of tissue injury caused by inflammatory and oxidative stress. J Nat Prod. 2011;74(3):537-45. https://doi.org/10.1021/ np100826q ((Epub 2011 Feb 10. PMID: 21309592; PMCID: PMC3064114)).

154. Ruiz S, Pergola PE, Zager RA, Vaziri ND. Targeting the transcription factor Nrf2 to ameliorate oxidative stress and inflammation in chronic kidney disease. Kidney Int. 2013;83(6):102941. https://doi.org/10.1038/ki.2012.439 ((Epub 2013 Jan 16. PMID: 23325084; PMCID: PMC3633725)).

155. Osburn WO, Yates MS, Dolan PD, Chen S, Liby KT, Sporn $\mathrm{MB}$, et al. Genetic or pharmacologic amplification of nrf2 signaling inhibits acute inflammatory liver injury in mice. Toxicol Sci. 2008;104(1):218-27. https://doi.org/10.1093/toxsci/ kfn079 ((Epub 2008 Apr 15. PMID: 18417483; PMCID: PMC2435415))

156. Reisman SA, Buckley DB, Tanaka Y, Klaassen CD. CDDOIm protects from acetaminophen hepatotoxicity through induction of Nrf2-dependent genes. Toxicol Appl Pharmacol. 2009;236(1):109-14. https://doi.org/10.1016/j.taap.2008. 12.024 ((Epub 2009 Jan 20. PMID: 19371629; PMCID: PMC2680225)).

157. Yates MS, Kwak MK, Egner PA, Groopman JD, Bodreddigari $\mathrm{S}$, Sutter TR, et al. Potent protection against aflatoxin-induced tumorigenesis through induction of Nrf2-regulated pathways by the triterpenoid 1-[2-cyano-3-,12-dioxooleana-1,9(11)-dien-28oyl]imidazole. Cancer Res. 2006;66(4):2488-94. https://doi.org/ 10.1158/0008-5472.CAN-05-3823 ((PMID: 16489057)).

158. Bonkowsky JL, Frazer JK, Buchi KF, Byington CL. Metamizole use by Latino immigrants: a common and potentially harmful home remedy. Pediatrics. 2002;109(6): e98. https://doi.org/10. 1542/peds.109.6.e98 ((PMID: 12042592)).

159. Sebode M, Reike Kunze M, Weidemann S, Zenouzi R, Hartl J, Peiseler M, et al. Metamizole: an underrated agent causing severe idiosyncratic drug-induced liver injury. Br J Clin Pharmacol.
2020;86(7):1406-15. https://doi.org/10.1111/bcp.14254 ((Epub 2020 Mar 3. PMID: 32080881; PMCID: PMC7319009)).

160. Björnsson ES. Liver injury associated with the analgetic drug metamizole. Br J Clin Pharmacol. 2020;86(7):1248-50. https:// doi.org/10.1111/bcp.14294 ((Epub 2020 May 12. PMID: 32400058; PMCID: PMC7319005)).

161. Santoiemma PP, Maddur H, Moore CM. A case of drug-induced liver injury secondary to natalizumab. Case Rep Hepatol. 2020;16(2020):7976585. https://doi.org/10.1155/2020/79765 85 ((PMID:32607262; PMCID:PMC7315275)).

162. LeSaint KT, Walsman J, Smollin CG. A case of teriflunomideinduced hepatic injury: assessing causality using available rules. Toxicol Commun. 2020;4(1):62-6. https://doi.org/10.1080/ 24734306.2020 .1835413$.

163. Potmešil P, Szotkowská R. Drug-induced liver injury after switching from tamoxifen to anastrozole in a patient with a history of breast cancer being treated for hypertension and diabetes. Ther Adv Chronic Dis. 2020;11:2040622320964152. https://doi. org/10.1177/2040622320964152.

164. Habib MB, Hanafi I, Al Zoubi M, Bdeir Z, Yassin MA. Severe and late acute liver injury induced by capecitabine. Cureus. 2021;13(1): e12477. https://doi.org/10.7759/cureus.12477.

165. Schlotman A, Stater A, Schuler K, Heideman J, Abramson V. Grade 3 hepatotoxicity following fulvestrant, palbociclib, and erdafitinib therapy in a patient with ER-positive/PR-negative/ HER2-negative metastatic breast cancer: a case report. Case Rep Oncol. 2020;13(1):304-8. https://doi.org/10.1159/000506442 ((PMID:32308596; PMCID:PMC7154258)).

166. Mascherona I, Maggioli C, Biggiogero M, Mora O, Marelli LA. A severe case of drug-induced liver injury after gemcitabine administration: a highly probable causality grading as assessed by the updated RUCAM diagnostic scoring system. Case Rep Hepatol. 2020;2020:8812983. https://doi.org/10.1155/2020/ 8812983.

167. Tan Y, Ye Y, Zhou X. Nilotinib-induced liver injury: a case report. Medicine (Baltimore). 2020;99(36): e22061. https:// doi.org/10.1097/MD.0000000000022061 ((PMID:32899072; PMCID:PMC7478446)).

168. Meynard L, Grellety T. CDK $4 / 6$ inhibitor successful rechallenge after limiting hepatic toxicity. Breast J. 2020;26(2):255-7. https://doi.org/10.1111/tbj.13532 ((Epub 2019 Sep 8 PMID: 31495008)).

169. Schosheim A, Mockler D, Chawla A. Does genetics play a role in acute liver injury after amoxicillin exposure? ACG Case Rep J. 2020;7(6): e00389. https://doi.org/10.14309/crj.0000000000 000389 .

170. Abbass A, Khalid S, Farooq U, et al. If DILI is suspected, don't dally. Dig Dis Sci. 2021;66(1):52-5. https://doi.org/10.1007/ s10620-020-06730-4.

171. Napier DJ, Bevan AV, di Mambro A. A fatal case of ciprofloxacin-induced fulminant hepatitis. Eur J Case Rep Intern Med. 2020;7(9): 001612. https://doi.org/10.12890/2020_001612 ((PMID:32908821; PMCID:PMC7473698)).

172. Teixeira M, Macedo S, Batista T, Martins S, Correia A, Matos LC. Flucloxacillin-induced hepatotoxicity: association with HLA-B*5701. Rev Assoc Med Bras. 2020;66(1):12-7. https:// doi.org/10.1590/1806-9282.66.1.12 (PMID: 32130375).

173. Hashim A, Barnabas A, Miquel R, Agarwal K. Successful liver transplantation for drug-induced vanishing bile duct syndrome. BMJ Case Rep. 2020. https://doi.org/10.1136/bcr-2019-233052.

174. Cheung S, Bulovic J, Pillai A, Manoj T, Neeraj K. A case of meropenem-induced liver injury and jaundice. J Community Hosp Intern Med Perspect. 2021;11(1):143-4. https://doi. org/10.1080/20009666.2020.1845929 ((PMID:33552438; PMCID:PMC7850334)) 
175. Li Y-J, Phillips EJ, Dellinger A, Nicoletti P, Schutte R, Li D, Ostrov DA, Fontana RJ, Watkins PB, Stolz A, Daly AK, Aithal GP, Barnhart H, Chalasani N. Human leukocyte antigen B*14:01 and $\mathrm{B} * 35: 01$ are associated with trimethoprim-sulfamethoxazole induced liver injury. Hepatology. 2021;73:268-81. https://doi. org/10.1002/hep.31258.

176. Varghese G, Madi L, Ghannam M, Saad R. A possible increase in liver enzymes due to amlodipine: a case report. SAGE Open Med Case Rep. 2020. https://doi.org/10.1177/2050313X20917822.

177. Hermida Pérez B, Izquierdo Romero M, García LR. Candesartaninduced cholestatic hepatitis: a case report. Rev Esp Enferm Dig. 2020;112(12):959-60. https://doi.org/10.17235/reed.2020.6988/ 2020 ((PMID: 33226250)).

178. de la Torre-Aláez M, Iñarrairaegui M. Drug liver injury induced by olmesartan mediated by autoimmune-like mechanism: a case report. EJCRIM. 2020. https://doi.org/10.12890/2020_001407.

179. de Célix CR, Serrano R, García-Buey L. Acute hepatitis due to olmesartan: an uncommon entity. Rev Esp Enferm Dig. 2020. https://doi.org/10.17235/reed.2020.7236/2020.

180. Al-Rifaie A, Khan MA, Ali A, Dube AK, Gleeson D, Hoeroldt B. Lisinopril-induced liver injury: an unusual presentation and literature review. Eur J Case Rep Intern Med. 2020;7(7): 001600. https://doi.org/10.12890/2020_001600.

181. Khan AA, Ahmed S, Mohammed A, Elzouki AY. Autoimmunelike drug-induced liver injury caused by atorvastatin and demonstration of the safety profile of pravastatin: a case report and literature review. Cureus. 2020;12(3): e7299. https://doi.org/10. 7759/cureus.7299.

182. Ma S, Liu S, Wang Q, Chen L, Yang P, Sun H. Fenofibrateinduced hepatotoxicity: a case with a special feature that is different from those in the LiverTox database. J Clin Pharm Ther. 2020;45(1):204-7. https://doi.org/10.1111/jcpt.13042 ((Epub 2019 Sep 13. PMID: 31518450; PMCID: PMC6973072)).

183. Mohamed M, Al-Hillan A, Flores M, Kaunzinger C, Mushtaq A, Asif A, et al. Concomitant acute hepatic failure and renal failure induced by intravenous amiodarone: a case report and literature review. Gastroenterol Res. 2020;13(1):40-3. https://doi.org/10. 14740/gr1254 ((Epub 2020 Feb 1. PMID: 32095172; PMCID: PMC7011916)).

184. Eslami V, Gheymati A. Clopidogrel-induced liver damage: a case report and review of the literature. Clin Case Rep. 2020;8(12):3024-7. https://doi.org/10.1002/ccr3.3324 ((PMID:33363872; PMCID:PMC7752642)).
185. Niu H, Sanabria-Cabrera J, Alvarez-Alvarez I, Robles-Diaz M, Stankevičiūtė $\mathrm{S}$, Aithal GP, et al. Prevention and management of idiosyncratic drug-induced liver injury: systematic review and meta-analysis of randomised clinical trials. Pharmacol Res. 2021;164: 105404. https://doi.org/10.1016/j.phrs.2020.105404 ((Epub 2020 Dec 24 PMID: 33359912)).

186. Moosa MS, Maartens G, Gunter H, Allie S, Chughlay MF, Setshedi M, et al. A Randomized controlled trial of intravenous $\mathrm{N}$-acetylcysteine in the management of anti-tuberculosis druginduced liver injury. Clin Infect Dis. 2020. https://doi.org/10. 1093/cid/ciaa1255 ((Epub ahead of print. PMID: 32845997)).

187. Kreitman K, Nair SP, Kothadia JP. Successful treatment of crizotinib-induced fulminant liver failure: a case report and review of literature. Case Reports Hepatol. 2020;10(2020):8247960. https://doi.org/10.1155/2020/8247960 ((PMID:32231818; PMCID:PMC7085870)).

188. Wu YQ, Liu LD, Wei HL, Liu GT. Different effects of nine clausenamide ennatiomers on liver glutathione biosynthesis and glutathione S-transferase activity in mice. Acta Pharmacol Sin. 2006;27(8):1024-8. https://doi.org/10.1111/j.1745-7254.2006. 00348.x ((PMID: 16867254)).

189. Wang M, Liu CY, Wang T, et al. (+)-Clausenamide protects against drug-induced liver injury by inhibiting hepatocyte ferroptosis. Cell Death Dis. 2020;11:781. https://doi.org/10.1038/ s41419-020-02961-5.

190. Wang X, Zhang H, Chen L, Shan L, Fan G, Gao X. Liquorice, a unique "guide drug" of traditional Chinese medicine: a review of its role in drug interactions. J Ethnopharmacol. 2013;150(3):781-90. https://doi.org/10.1016/j.jep.2013.09.055 ((Epub 2013 Nov 5 PMID: 24201019)).

191. Wu SY, Wang WJ, Dou JH, Gong LK. Research progress on the protective effects of licorice-derived 18 $\beta$-glycyrrhetinic acid against liver injury. Acta Pharmacol Sin. 2021;42(1):18-26. https://doi.org/10.1038/s41401-020-0383-9.

192. Chung JY, Longo DM, Watkins PB. A rapid method to estimate hepatocyte loss due to drug-induced liver injury. Clin Pharmacol Ther. 2019;105(3):746-53. https://doi.org/10.1002/cpt.1254 ((Epub 2018 Nov 2 PMID: 30303523)).

193. Drug-induced liver injury (DILI): current status and future directions for drug development and the post-market setting. A consensus by a CIOMS Working Group. Geneva: Council for International Organizations of Medical Sciences (CIOMS); 2020. 